\title{
Trajectories of Regenerating Retinal Axons in the Goldfish Tectum: II. Exploratory Branches and Growth Cones on Axons at Early Regeneration Stages
}

CLAUDIA A.O. STUERMER

Friedrich-Miescher-Laboratorium der Max-Planck-Gesellschaft, 7400 Tuebingen, Federal Republic of Germany

\begin{abstract}
HRP was applied to small sites in the dorsotemporal or dorsonasal retina in fish at 10-36 days after optic nerve section. The anterogradely labeled axons were visualized in tectal whole mounts.

Axons traveled through all regions of the tectum in various abnormal routes. Misrouted axons were also seen to alter their orientation and to direct their course toward their target. At all regeneration stages the majority of dorsotemporal axons coursed and achieved target-related orientations preferentially within the rostral tectal half whereas dorsonasal axons proceeded into the caudal tectum.

The growing axons exhibited various morphologies. All axons in the superficial fascicle layer stratum opticum (SO) and some in the synaptic layer stratum fibrosum et griseum superficiale (SFGS) were unbranched and tipped with a leading growth cone. Other axons in the synaptic layer carried one to several growth cones at their ends and often filopodia proximal to the growth cone, or they had sprouted numerous side branches with growth cones and filopodia on the shaft and on branches. Some axons at retinotopic or ectopic sites gave rise to several long branches of several hundred microns in length, with growth cones and filopodia. From 32 days onward axons ending in terminal arbors at retinotopic sites became apparent. Thus, numerous axons at early regeneration stages go through a phase of exploratory growth on their way toward their target sites.
\end{abstract}

Key words: regenerating retinotectal axons, abnormal paths, anterograde HRP staining, tectal whole mounts

The reliability with which regenerating retinal axons in lower vertebrates restore a retinotopic organization of their terminal arbors is remarkable (Attardi and Sperry, '63; Gaze, '70). The reformation of the retinotopic map is even more surprising in the light of recent findings that show that the recreation of a retinotopic terminal order does not depend on a normal pathway organization (Udin, '78; Meyer, '80; Fujisawa et al., '82; Cook, '83; Stuermer and Easter, '84; Taylor and Gaze, '85; Stuermer, '86, '87b). After optic nerve section the regenerating axons lose their original spatial order and travel in abnormal routes through the optic nerve and tract (Fawcett and Gaze, '81; Stuermer and Easter, '84; Stuermer, '86), enter the tectum in anomalous positions, and project to their target sites in ways not seen in the normal animal (Fujisawa, '81; Taylor and Gaze, '85; Stuermer and Easter, '84; Stuermer, ' 86 ; '87b). On the basis of this knowledge it remains to be determined how the regenerating axons might interact with the tectum and manage to gain access to their target.

Although disputed in the past (Attardi and Sperry, '63; Horder, '74) there is now clear evidence for a progressive reorganization of the tectal innervation pattern during optic nerve regeneration in fish. Counts of axonal profiles at the electron-microscopic level have shown an increased number of axons at early regeneration stages and a subsequent decline at later stages of regeneration (Murray and Edwards, '82). Further, electrophysiological and anatomical mapping experiments have revealed that the order of the early projection differs from that at late-regeneration stages in that the map is initially diffuse but gradually

Accepted June 17, 1987. 


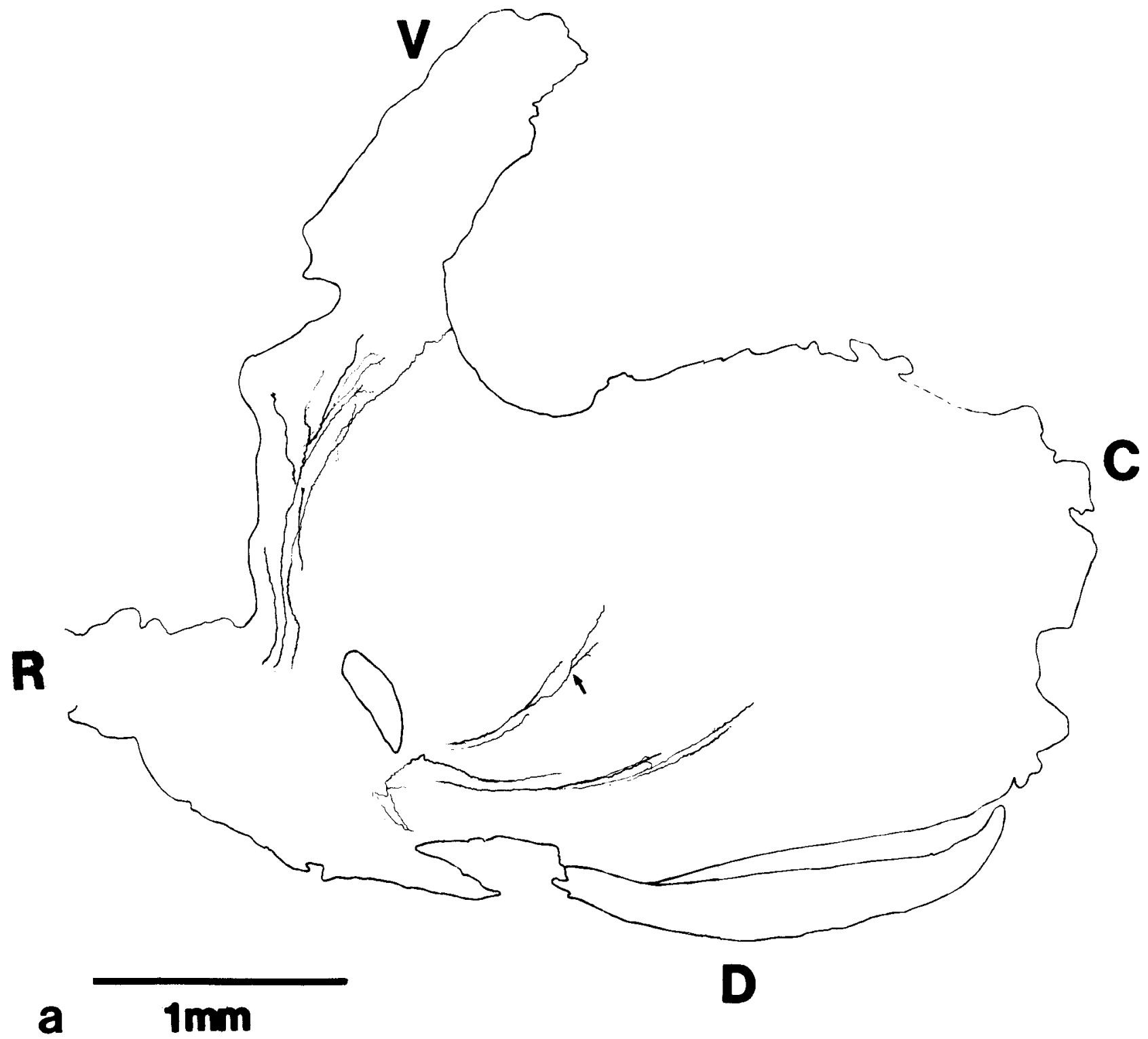

Fig. 1. Camera lucida tracings of tectal whole mounts at 14 days after optic nerve section. a: Dorsotemporal axons. b: Dorsonasal axons. Dorsotemporal axons were confined to the rostral tectal half whereas dorsonasal axons had progressed into caudal tectum. Arrows mark axonal branch points. The stippled region in $b$ indicates a hole in the preparation. Abbreviations: $\mathrm{R}=$ rostral, $\mathrm{C}=$ caudal, $\mathrm{D}=$ dorsal, $\mathrm{V}=$ ventral refines to normal precision (Jacobson and Gaze, '65; Meyer, '80; Humphrey and Beazley, '82; Northmore and Masino, '84; Meyer et al., '85; Rankin and Cook, '86). None of these mapping experiments, however, provided information on the morphology of the regenerating axons. By visualizing HRP-stained axons in tectal whole mounts, Schmidt ('85) detected axonal arborizations of unusually large dimensions during the early diffuse stages of regeneration. Later, when the map was refined, terminal arbors of normal sizes were encountered (Schmidt, '85). This finding accounts, at least in part, for the diffuseness of the early map. Since the axons were labeled in the optic tract, the authors were not able to relate the position of the arborizations to their ganglion cells of origin and to their destination in the tectum. And it remains an open question whether the axons first navigate into the general vicinity of their target and then begin to arborize (Meyer et al., '85) or whether they extend branches on the way to their target (Fujisawa et al., '82). Fujisawa et al. ('82) traced the path of axons from known retinal origin at early regeneration stages in the newt. In this animal, the misrouted axons produced numerous side branches into various directions in the tectum prior to the arrival at their destination. These ectopic branches disappeared when the axons had reached their retinotopic termination sites. Here they gave rise to a densely branched mature terminal arbor. The authors concluded that the regenerating axons navigate to their target by preferential selection of appropriate, and elimination of ectopic, branches (Fujisawa et al., '82).

A documentation of the paths and the morphologies of growing axons destined for known territories in the tectum is not available for fish, since it is difficult to stain the 


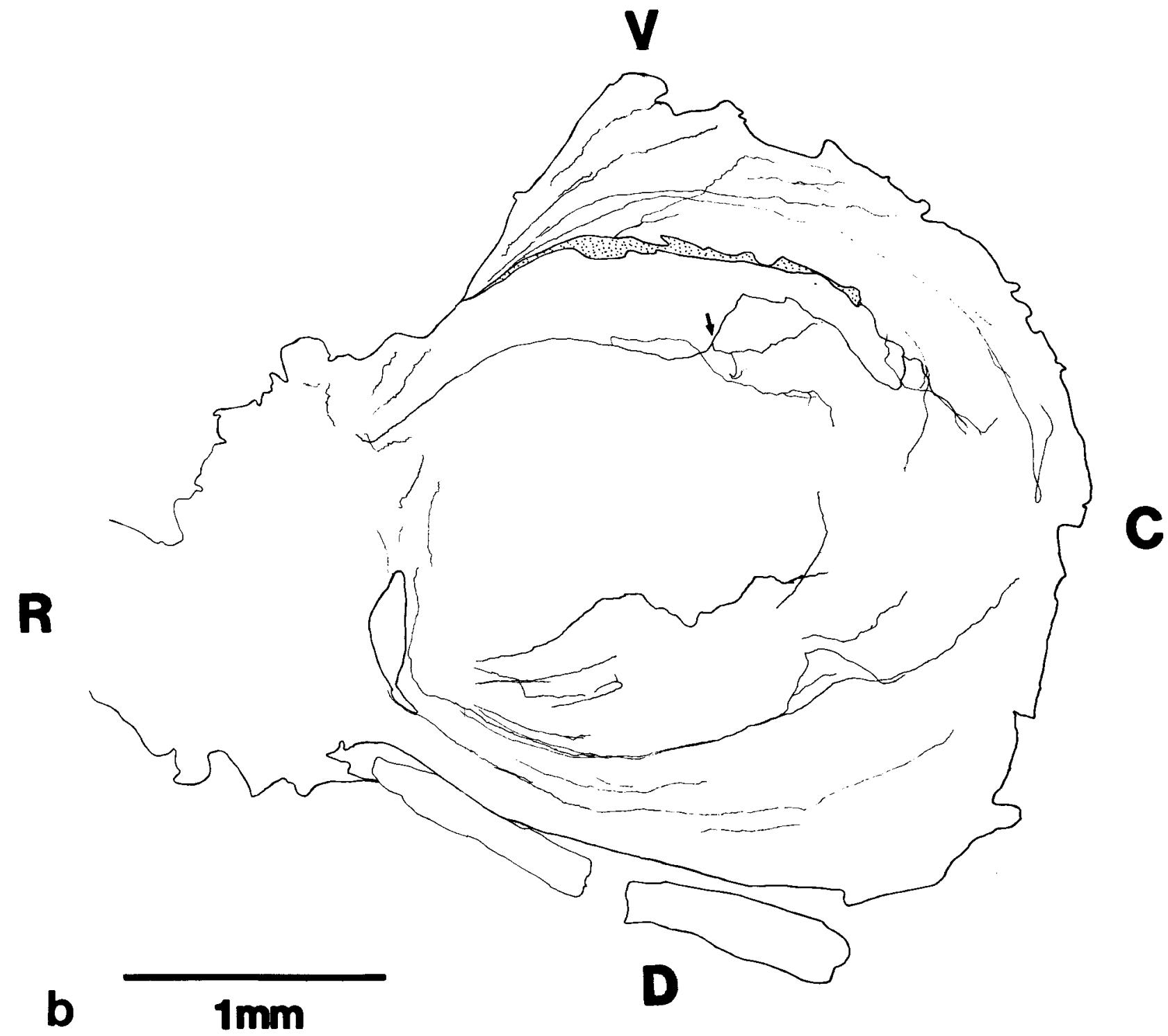

Figure 1 continued

growing axons. Such information, however, will help us to understand the mechanisms by which the growing axons succeed in finding their retinotopic regions.

The current report analyzes the morphological characteristics of the regenerating axons at early regeneration stages in goldfish. The growing axons were labeled by applications of HRP into defined regions of retina. This allowed the determination of the path of axons toward their target and the investigation of their morphological features. Because of modified staining procedures, the growing axons exhibited staining properties that were superior to those reported in previous studies (Fujisawa et al., '82; Taylor and Gaze, '85; Schmidt, '85) that allowed visualization of growth cones and filopodia.

The result were published in part as abstracts (Stuermer et al., '85, '86a,b) and were included in a review (Stuermer, '87a).

\section{MATERIALS AND METHODS}

To label regenerating axons of defined retinal origin, HRP was applied to severed axons in the dorsotemporal and dorsonasal retina between 10 and 35 days after optic nerve section. Four to five days were allowed for anterograde transport and/or diffusion of HRP. The HRP-labeled axons were visualized in tectal whole mount preparations. Details on the experimental procedures are described in the companion paper (Stuermer, '87b). The quantitative approach to determine the distribution and orientation of the regenerating axons is also given in the companion paper (Stuermer, '87b).

\section{RESULTS}

The analysis of the axonal trajectories at late-regeneration stages 3-12 months after optic nerve section reveal 


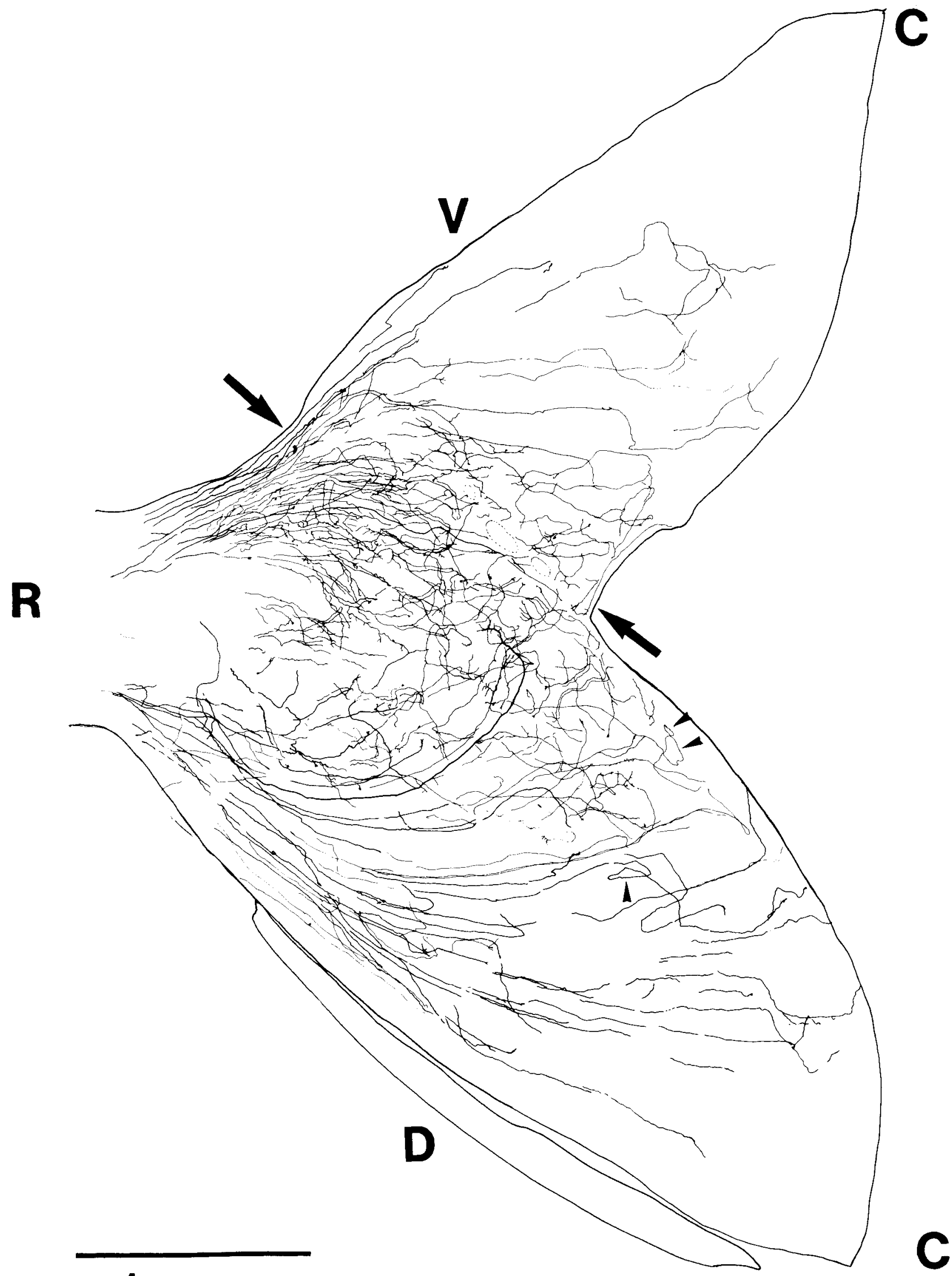

\section{$1 \mathrm{~mm}$}

Fig. 2. Dorsotemporal axons in a tectal whole mount at 28 days after optic nerve section. Labeled axons course in various abnormal routes through all regions of tectum, but most are in the more rostral tectal half. The approximate location of the retinotopic target region is marked by two arrows. Arrowheads point to loops of axons in the caudal tectum. Abbreviations as in Figure 1. 


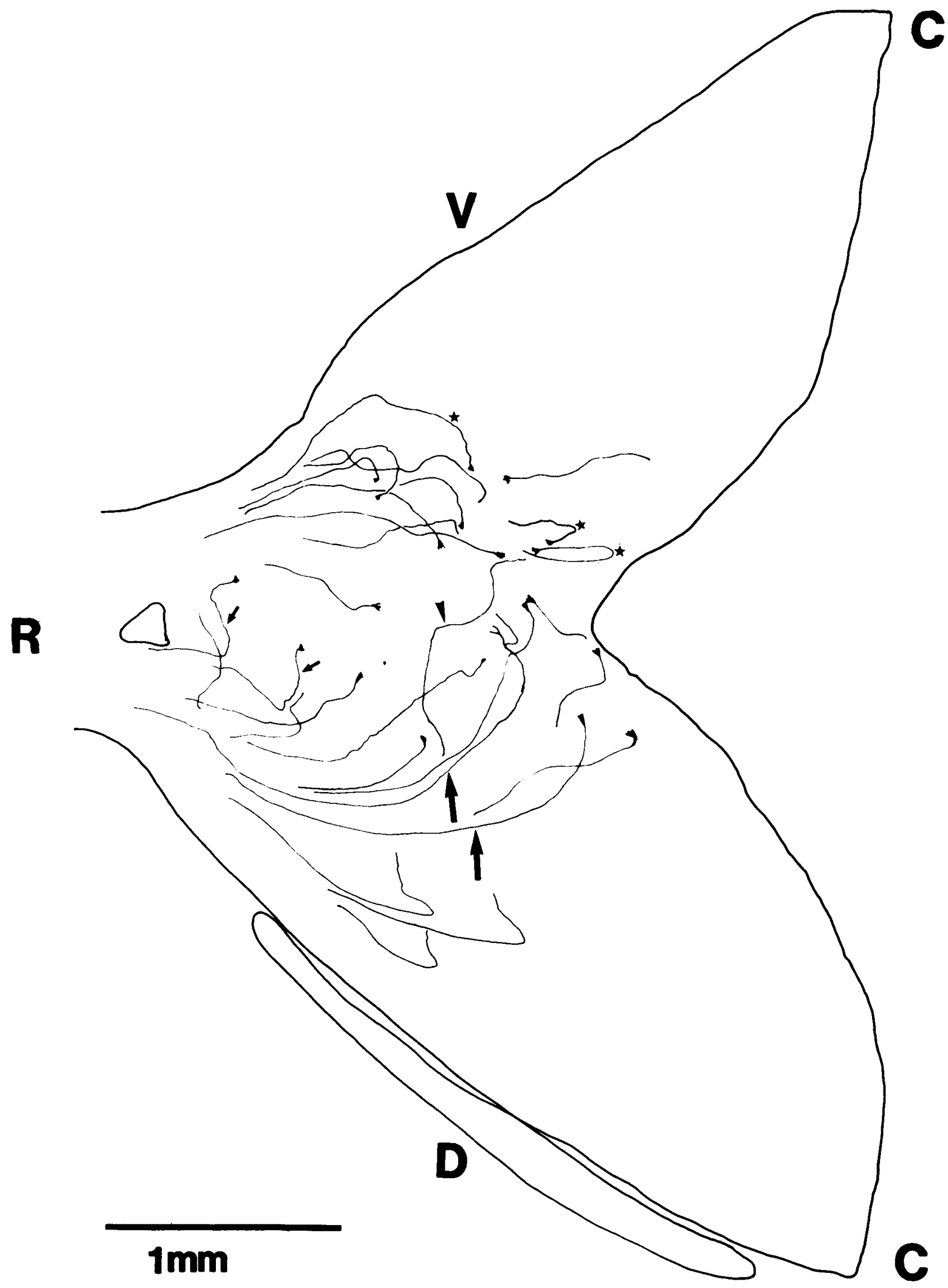

Fig. 3. Typical examples of routes of unbranched axons with leading growth cones. Axons begin to establish or have established routes with orientations toward their target region. Misrouted axons in the dorsa hemitectum either bend abruptly in stratum fibrosum et griseum superfi-

ciale (SFGS, small arrows and arrowhead) or they follow routes of the fascicles in stratum opticum (SO, larger arrows) and course toward ventra hemitectum. Axons in the ventral hemitectum that had passed the retinotopic region return directly or more gradually into rostral directions. 


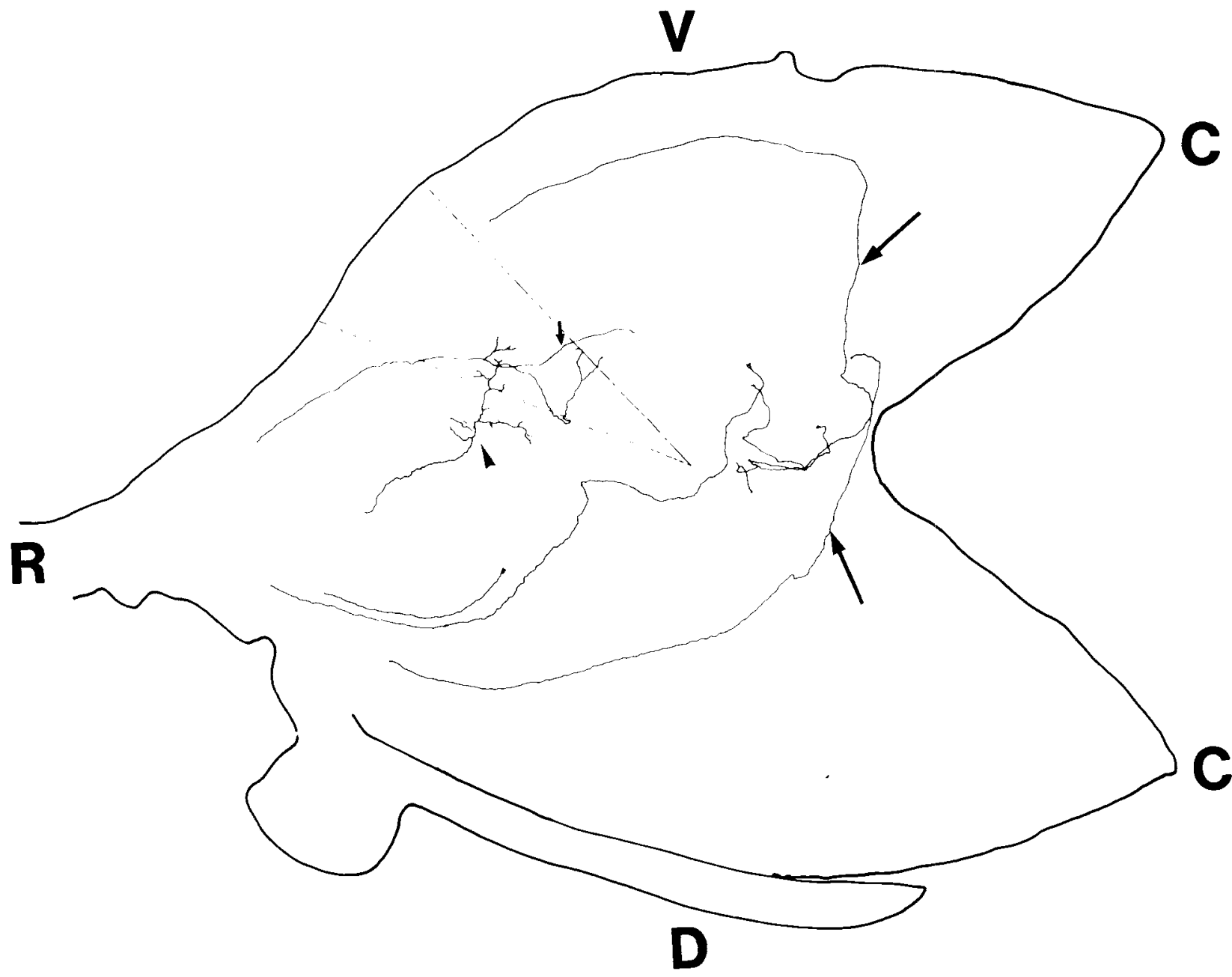

\section{$1 \mathrm{~mm}$}

Fig. 4. Camera lucida tracing of paths of individual dorsotemporal axons of a tectum 32 days after optic nerve section. Arrows point to axons that returned from more caudal tectal regions into rostral directions. An imma. ture arbor (arrowhead) is located in the vicinity of the retinotopic region (dashed lines) next to an axon with branches more widely spaced (small arrow). Abbreviations as in Figure 1. that the regenerating dorsotemporal and dorsonasal axons reach their target in direct routes or with abrupt or gradual course corrections when misrouted (Stuermer, '87b). Whether regenerating axons at early regeneration stages, 10-35 days postnerve transection, course over these routes immediately to their target or whether they might exhibit signs of exploratory growth was tested by visualizing the trajectories of dorsotemporal and dorsonasal axons at early regeneration stages between 10 and 19 days $(\mathrm{N}=34)$ and 25 and 36 days $(\mathrm{N}=40)$ after optic nerve section.

After application of HRP in the dorsotemporal or dorsonasal retina the axons in tectum were well stained including their branches, growth cones, and filopodia (Figs. 5, 6). The first dorsonasal and dorsotemporal axons invaded rostrally into the ventral and dorsal hemitectum between days 10 and 12 after optic nerve section and advanced in a roughly caudal direction. Between days 12 and 14, the dorsonasal axons had reached into the far caudal tectum (Fig. 1b) whereas dorsotemporal axons remained in the rostral tectum (Fig. 1a). Camera lucida tracings of a left and a right tectum of one fish at 14 days after bilateral optic nerve section (Fig. 1) illustrate this differential distribution of dorsonasal and dorsotemporal axons.

Axons at this stage were generally of simple morphology in that most were unbranched and tipped with a single leading growth cone. A very few axons had given rise to one or two side branches (Fig. 1). Course alterations that were typical for misrouted axons at later-regeneration stages were not yet apparent.

At progressively later times many more axons arrived in the tectum and they developed more complex morphologies. The routes of these axons and their morphological characteristics are shown in camera lucida tracings of typical examples between 25 and 36 days.

\section{Dorsotemporal axons}

A camera lucida tracing of a tectum with labeled dorsotemporal axons at 28 days is shown in Figure 2 . It is readily appreciable from Figure 2 that most labeled axonal profiles were present over the rostral tectal half and fewer over caudal tectum. 

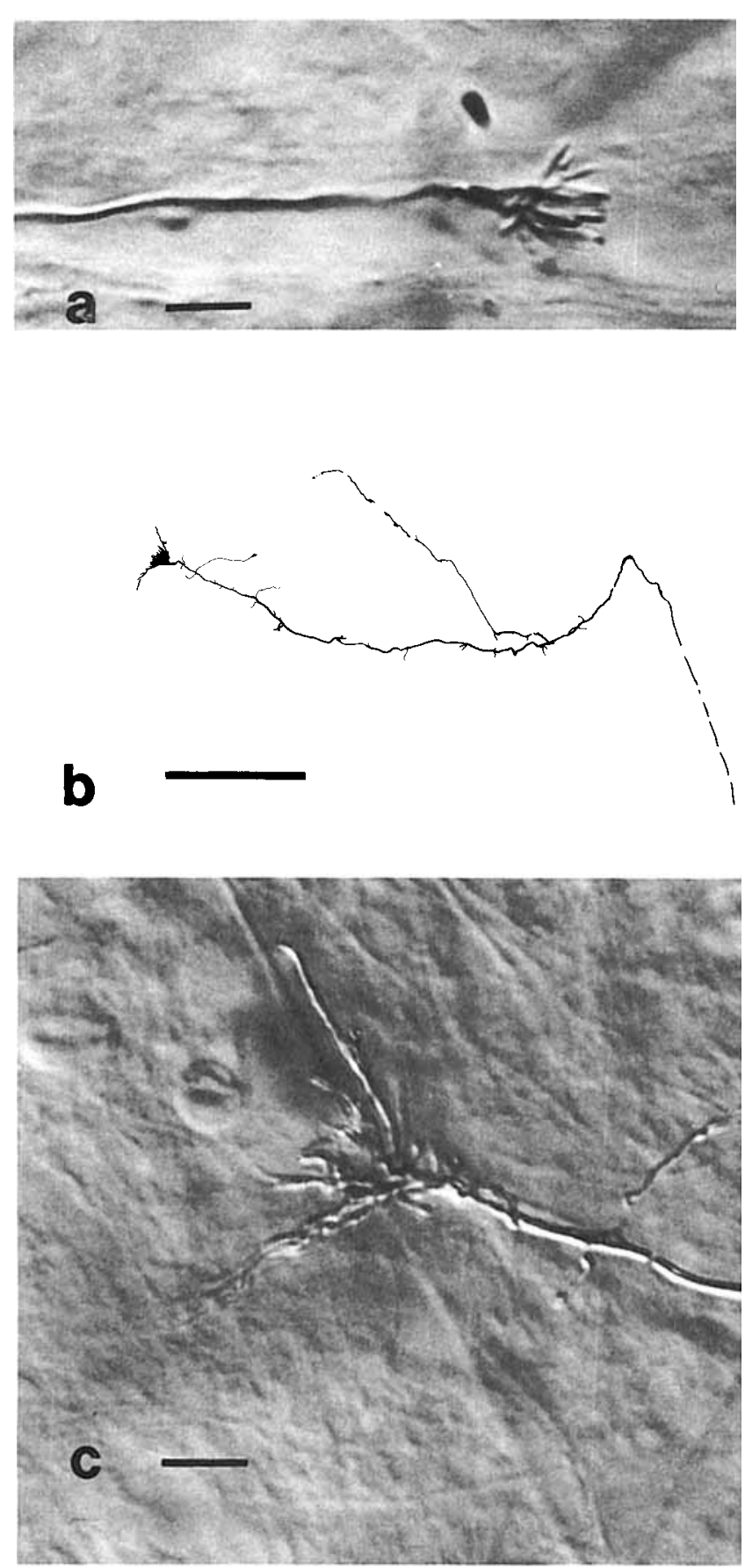

Fig. 5. a: Photomicrograph of an HRP-labeled unbranched axon in SO with a leading growth cone, from the tectum in Figure 3. b: Camera lucida tracing and photomicrograph of an HRP-labeled axon and its growth con in SFGS, from the tectum in Figure 3. Numerous filopodia and a vestigal branch are seen proximal to the growth cone. c: Photomicrograph of the growth cone shown in b. Calibration bars in a,c: $10 \mu \mathrm{m}$; in b: $100 \mu \mathrm{m}$.

Between 28 and 36 days, only a fraction of the dorsotemporal axons had reached their appropriate retinotopic regions. Instead most coursed in various regions of the tectum and exhibited a variety of growth-related morphological characteristics.

Axons that had approached their target or traveled in target-directed orientation had established normal and various abnormal routes that were in principal similar to those at late-regeneration stages (Figs. 2 and 4 in Stuermer '87b, companion paper). These routes were most obvious for axons that were unbranched for most of their extent. Figure 3 depicts typical examples from the tectum shown in Figure 2 .

From their rostral point of entrance axons on the correct ventral hemitectum coursed either more or less directly toward their target or turned back in the direction of the target site if they had passed beyond it (Figs. 3, 4).

Axons entering the inappropriate dorsal hemitectum used three strategies to navigate into the ventral hemitectum. Some bent in sharp angles shortly after their entrance into the tectum to course through the synaptic layer in the direction of the target (Figs. 2, 3); others ran through the synaptic layer obliquely across the rostral tectum; still others followed the routes of the previous fascicles in the superficial fiber layer for variable extents and then achieved target-related orientations (Figs. 2-4). Fewer axons, but more than at late-regeneration stages, wandered through the far caudal tectum without obvious target-related orientations. They occasionally exhibited one or two circular loops (Fig. 2). In the tectum of Figure 2 at 28 days postnerve transection, axons in the caudal tectum did not yet exhibit signs of target-related course correction. However, in a tectum of a slightly later stage, at 32 days, such axons with course alterations were seen and typical examples are illustrated in Figure 4.

On the basis of their appearance the regenerating axons between 25 and 36 days after optic nerve section fell into several categories. They were unbranched except for occasional filopodial sprouts throughout their course through the fiber and synaptic layer and carried simple growth cones at their tips (Fig. 5a). Other axons with growth cones in the synaptic layer had numerous filopodia on the axonal shaft proximal to the growth cone and an occasional side branch (Fig. 5b). Some axons in the synaptic layer had divided ends, most with growth cones on their tips. Yet another group in the synaptic layer but absent from the fiber layer had numerous short side branches with filopodia and growth cones or even nests of growth cones on each of the branches and on the axonal shaft. One typical example is shown in Figure 6. The side branches appeared on stretches of the axons over $800 \mu \mathrm{m}$. At least ten growth cones were identified on this axon. Another axon that probably had come from the dorsal hemitectum ran from the tectal equator in a mediolateral direction, and branches and growth cones appeared over $500 \mu \mathrm{m}$ on the axon's more distal end (Fig. 7b). A fifth group in the synaptic layer gave rise to long branches of several hundred microns in length. The branches were in some instances widely spaced over the axon (Fig. 7c) or emerged close together as terminal branches from the axon's leading end (Fig. 8). Most of these terminal branches were studded with growth cones and filopodia. The terminal branches resided in the retinotopic region as well as at ectopic sites. Figure 8 shows three examples from the tectum in Figure 2.

The axon in Figure $8 \mathrm{~b}$ had followed the route of an intermediate fascicle in the dorsal hemitectum and then emitted several branches, most of which were oriented toward the target. Filopodia were abundant on all branches and growth cones emerged from the axonal shaft. The axon in Figure $8 \mathrm{~d}$ branched at ectopic sites in the dorsocaudal tectum, and growth cones arose from all branches. The branches of the axon in Figure 8c at ectopic sites in the ventrocaudal tectum were oriented into caudal, central, and rostral direc- 


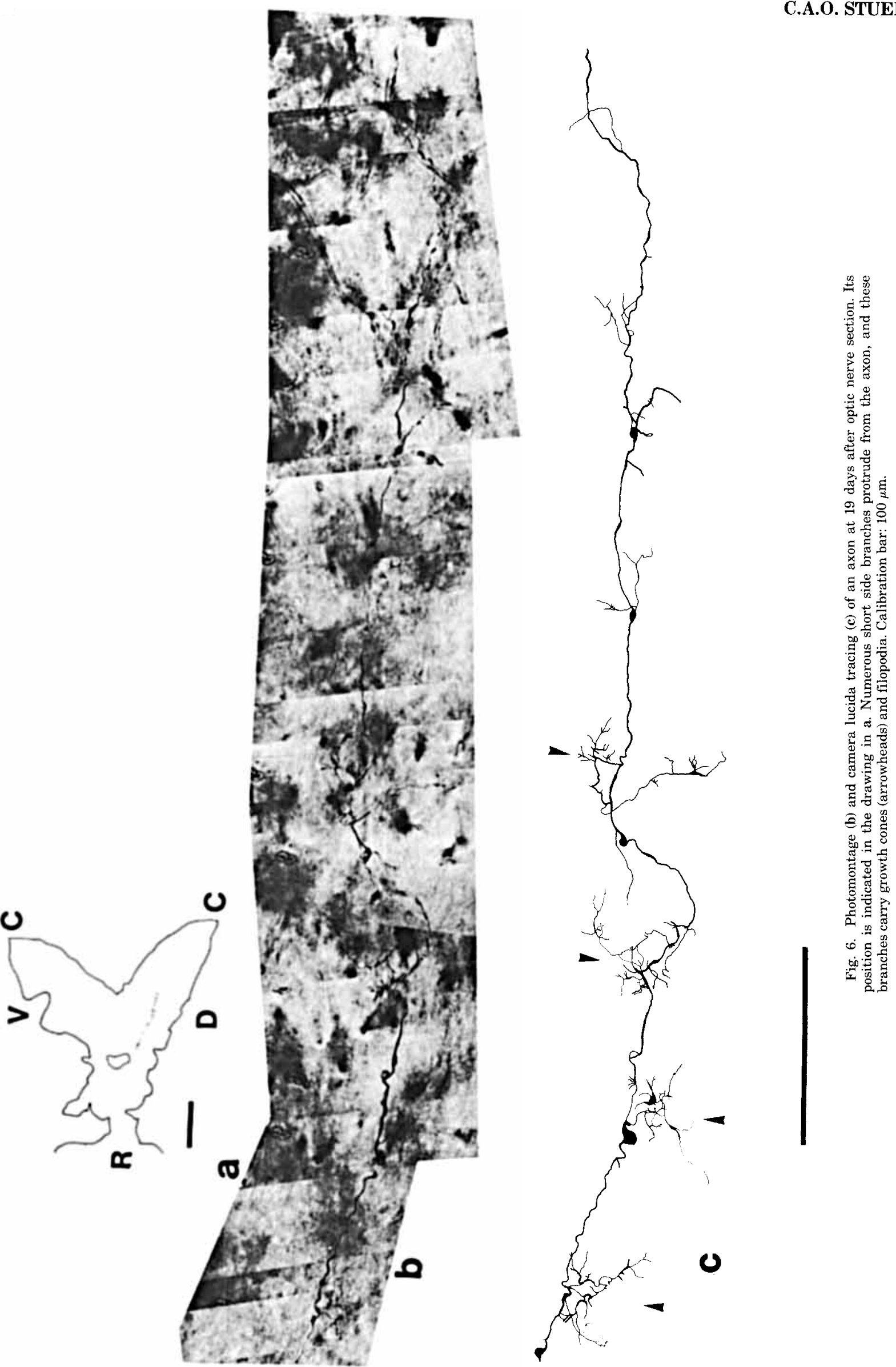



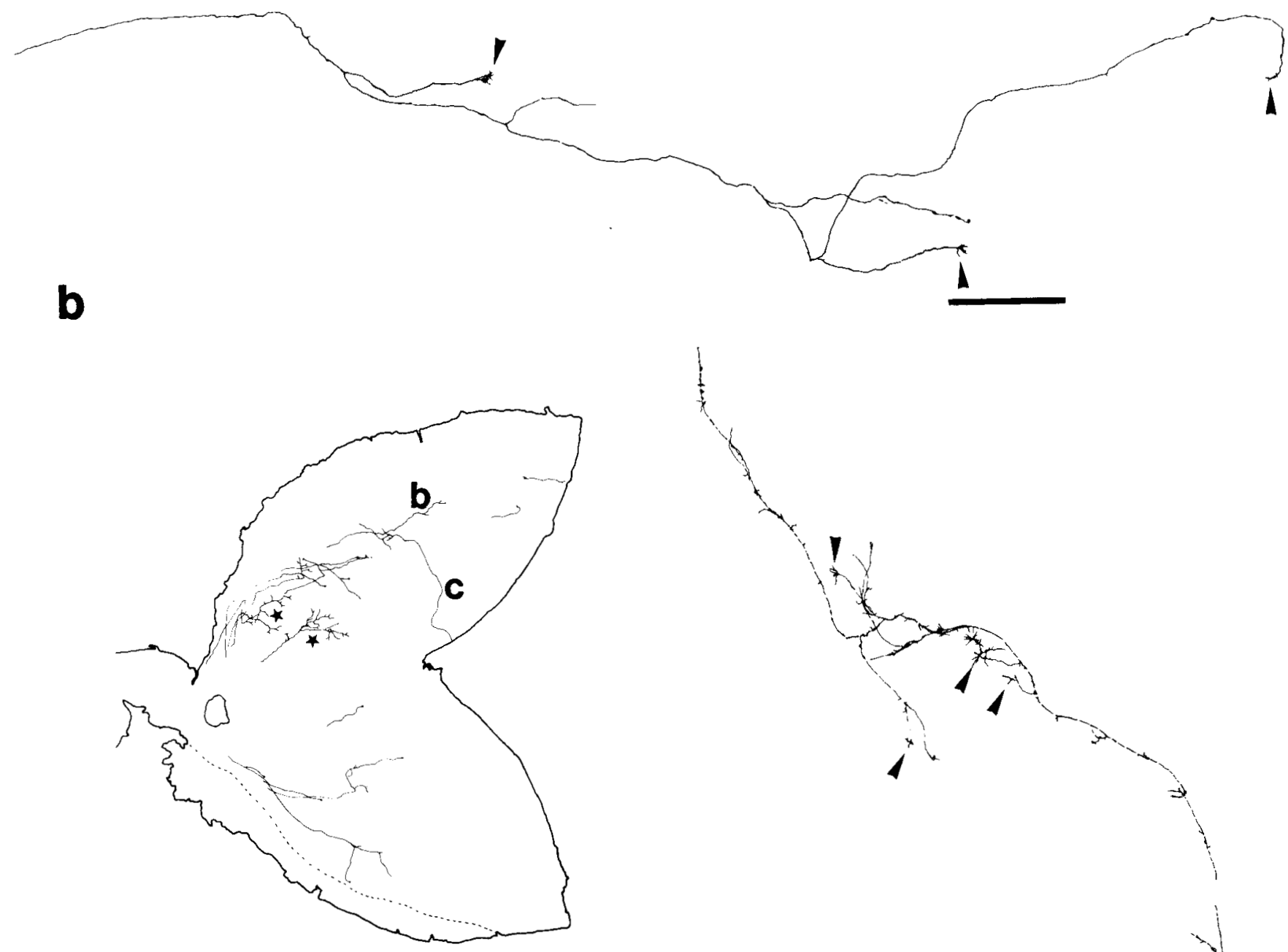

a

Fig. 7. b,c: Camera lucida tracings of axons at 36 days after optic nerve section. Their positions are marked in $\mathbf{a}$. The axon in $\mathbf{b}$ has numerous short branches with growth cones (arrowheads) over its distal segment. The axon growth cones (arrowheads). The stars mark two terminal arbors at retino topic sites, which are shown enlarged in Figure 9. Calibration bars: a, 1mm, in $c$ has longer branches that are more widely spaced. Three branches carry b and $\mathbf{c}, 100 \mu \mathrm{m}$ 


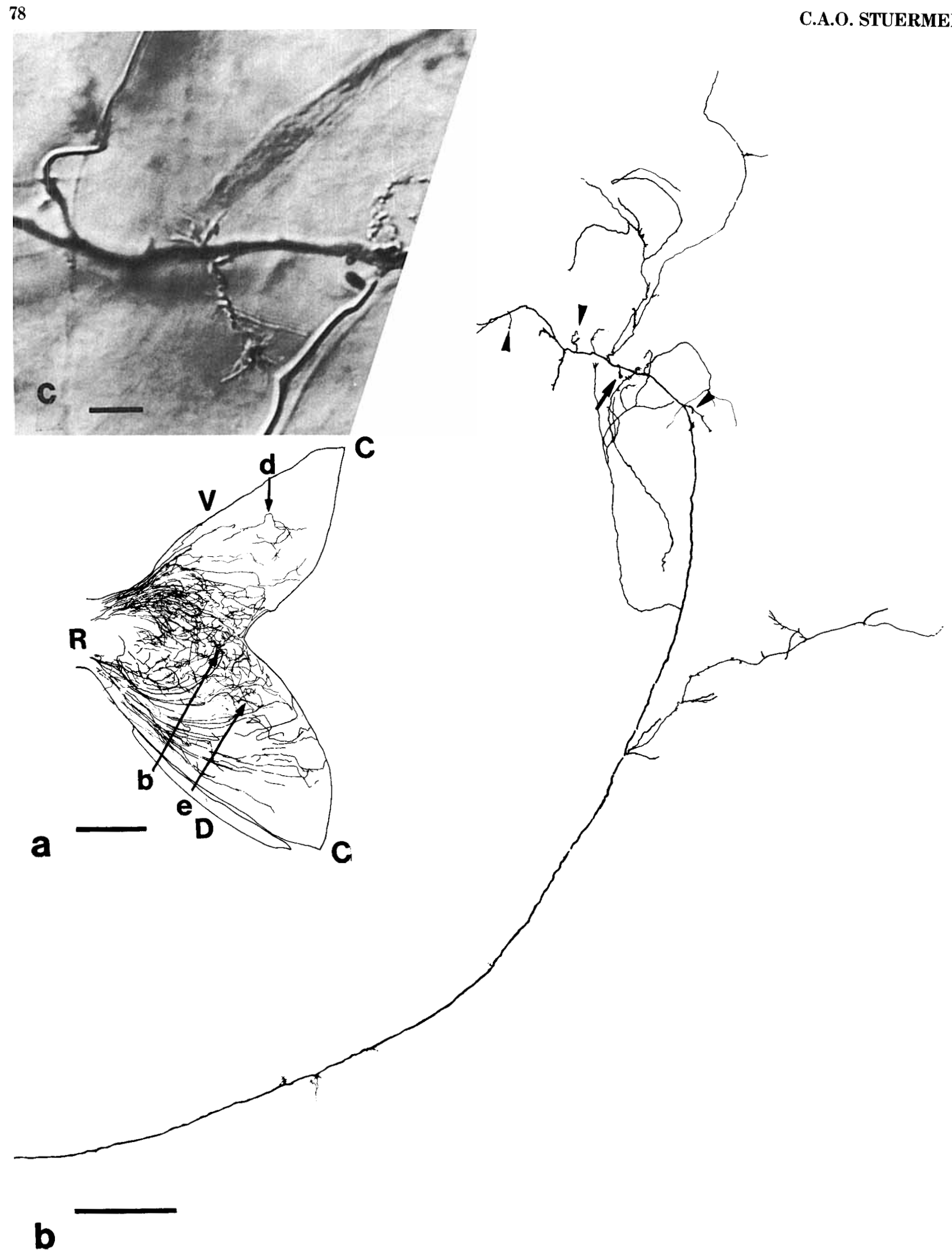




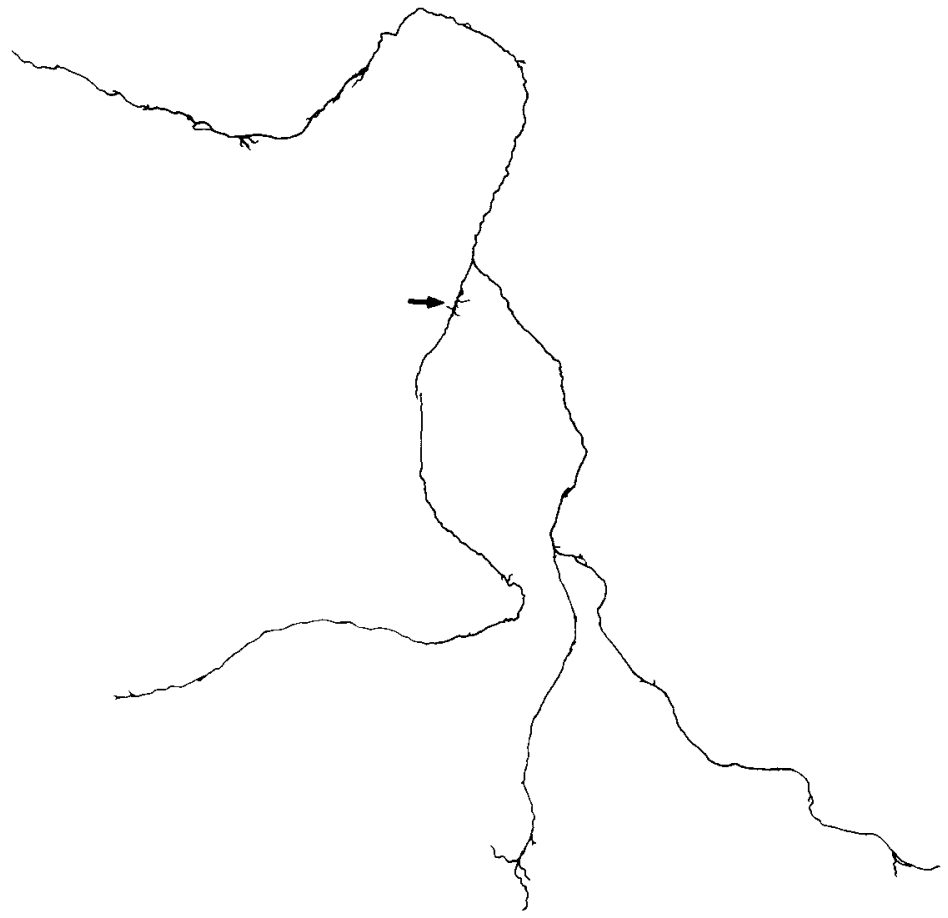

d

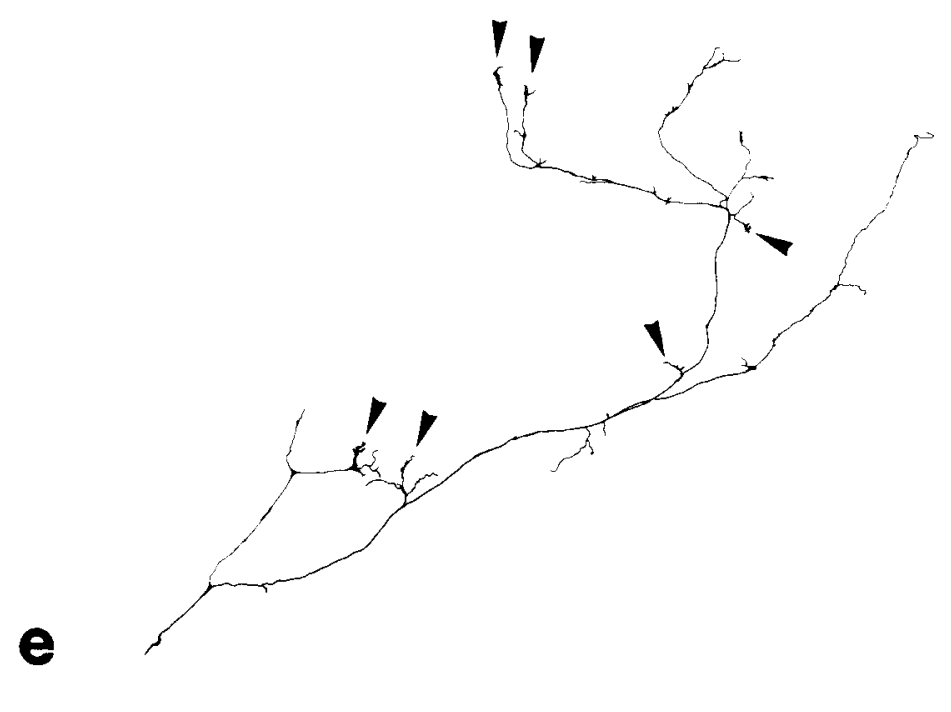

Fig. 8. b,d,e: Camera lucida tracings of axonal ramifications from the tectum depicted in Figure 3 and in Figure 8a, where the position of these axons is indicated. $\mathbf{b}$ : This axon came over a fascicle in the dorsal hemitec tum and began to emit branches with filopodia in a layer just deep to the fascicles. Short branches on the axonal shaft carry growth cones (arrowheads). c: Photomicrograph of a growth cone (arrow in b) emerging from the

axonal shaft. d: This axon had branched in the ventrocaudal tectum. Arrow points to short filopodia. e: Axons that give rise to branches with growth cones (arrowheads) and filopodia in the dorsocaudal tectum. Abbreviations in a in Figure 1. Calibration bar in b,d,e, $100 \mu \mathrm{m}$; in a, $1 \mathrm{~mm}$; in c, 10 $\mu \mathrm{m}$. 


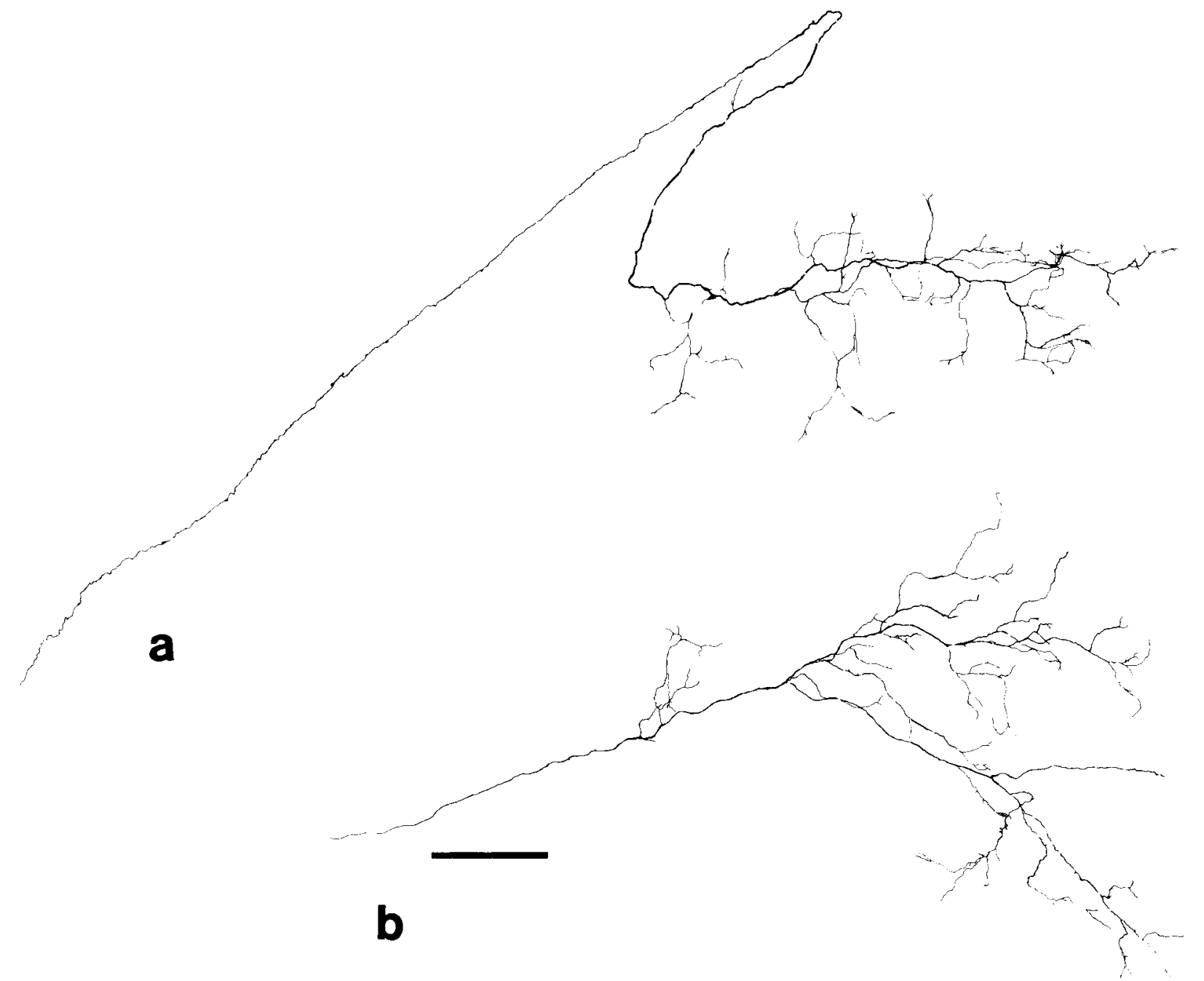

Fig. 9. Two terminal arbors of dorsotemporal axons from a tectum at 36 days after optic nerve section. The arbors reside at retinotopic regions and their position is indicated in Figure 8a. Calibration bar: $100 \mu \mathrm{m}$.

tions. They were without growth cones but had filopodia.

From 32 days onward a few axons were noted that began to produce a terminal arbor in the vicinity of the retinotopic region. One example is included in Figure 4. Coexistent with such immature arbors were axons with branches that were more widely spaced over the axon's distal segment (Fig. 4). In a tectum at 36 days some axons ended in terminal arbors at retinotopic sites that resembled more closely those seen in normal tecta and in tecta at late-regeneration stages. The axonal shaft had thickened at its distal end Numerous side branches protruded from the thickened end and these branches divided further into secondary and tertiary branches (Fig. 9). Such terminal arbors were found consistently in tecta from 36 days onward and were only seen once in a tectum as early as 18 days after optic nerve section. It cannot be excluded that terminal arbors may be present in the intervening time periods as well, but they might have been missed due to the high density of labeled axonal profiles close to the target region.

\section{Dorsonasal axons}

Like dorsotemporal axons, the dorsonasal axons at survival stages between 25 and 36 days after optic nerve section branched on their way through tectum. Branching occurred preferentially in the caudal tectum so that the density of labeled dorsonasal axons was higher in the caudal than in the rostral tectum. This is visible in the camera lucida tracing of a tectum at 28 days with labeled dorsonasal axons (Fig. 10).

The axonal routes were generally similar to those seen for dorsonal axons at late-regeneration stages (compare Fig. 6 in Stuermer, '87b, companion paper). From their rostral point of entrance part of the axons followed the routes of the previous fascicles (Figs. 10, 11). Axons in more peripheral fascicles were led into caudal tectum (Figs. 10, 11 and axon No. 2 and 7 and 8 in Fig. 12). The routes of rostral and intermediate fascicles ended close to the tectal equator at more rostral levels. Here, axons entered into the synaptic layer to course either caudally (Fig. 10, axon No. 4 in Fig. 12 ) or obliquely across the tectal equator (Fig. 11). Axons ran also from rostral to caudal tectum in a layer just deep to the fascicles where they exhibited more tortuous trajectories.

Axons in these routes, similar to dorsotemporal axons, were either unbranched throughout most of their course and tipped with growth cones or they had branched endings with growth cones. Other axons were smooth as long as they followed the fascicle route but exhibited numerous 


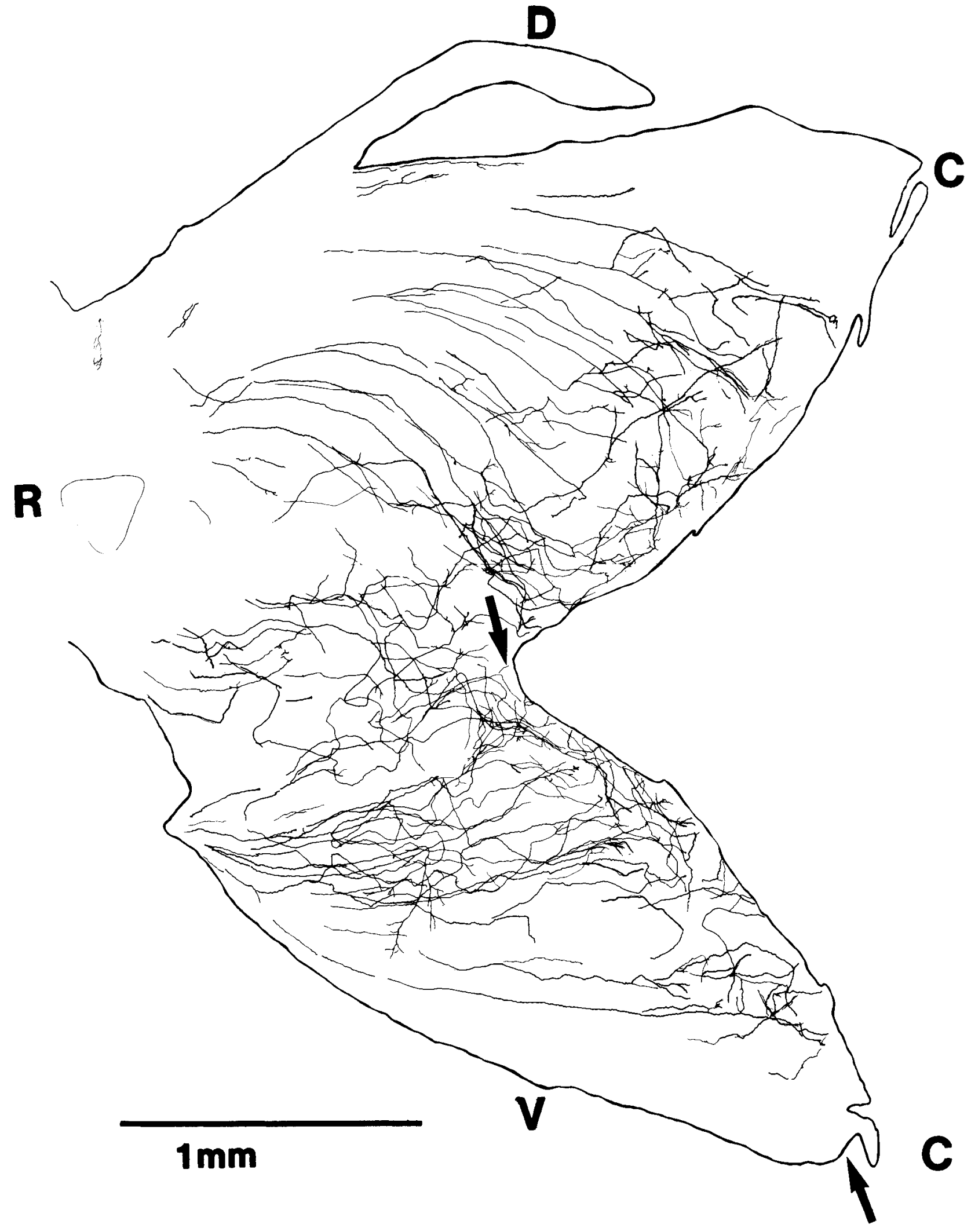

Fig. 10. Camera lucida tracing of a tectal whole mount with dorsonal axons 28 days after optic nerve section. Numerous axons had progressed into caudal tectum and branched. Arrows indicate the approximate position of the retinotopic target region. Abbreviations as in Figure 1. 


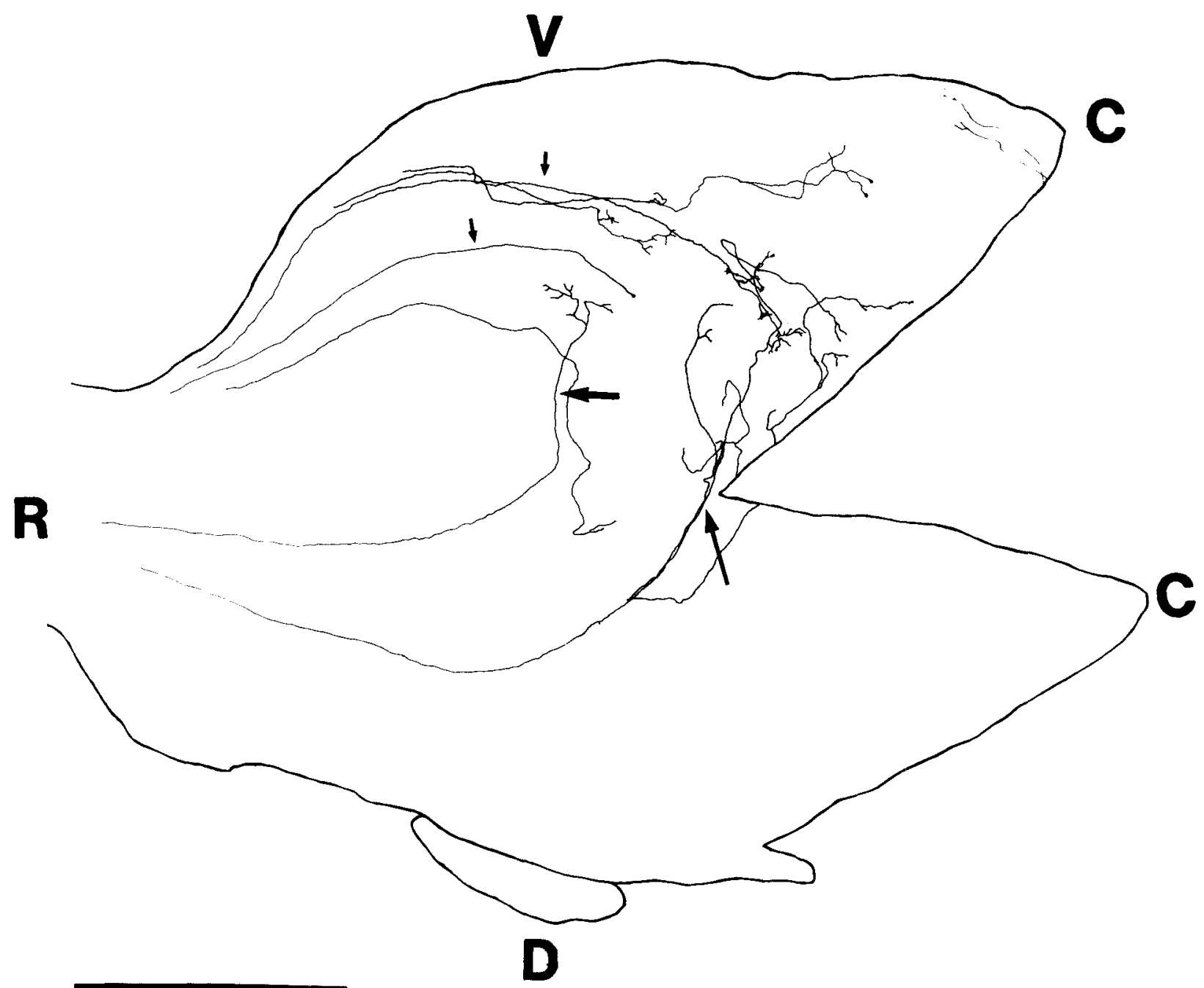

$1 \mathrm{~mm}$

Fig. 11. Camera lucida tracing of paths of individual dorsonasal axons in a tectum at 32 days after optic nerve section. Axons in fascicular routes on the ventral hemitectum are marked by small arrows. The two larger arrows point to axons that cross from the dorsal into the ventral hemitectum. Abbreviations as in Figure 1.

side branches of variable length after they had entered into the synaptic layer SFGS. Axons 1, 2, 4, 7, and 8 in Figure 12 are typical examples. Axons with long branches emerging from the distal end of the axon were also encountered (axons 3 and 5 in Fig. 12). Those occurred at various sites within the caudal tectum and on occasion in the rostral tectum (No. 5 in Fig. 12). Only observed once was an axon that had split into five long branches in rostral tectum. The branches were oriented in a caudal direction and three of them carried growth cones (No. 6 in Fig. 12). Terminal arbors such as those shown in Figure 9 were found at retinotopic sites in tecta from approximately 32 days onward.

Thus part of the regenerating axons establish routes that persist at late-regeneration stages. They either are un branched throughout the path to their target region or emit branches while navigating through tectum.

\section{A quantitative evaluation of the distribution and orientations of regenerating dorsotemporal and dorsonasal axons}

The impression gained from tracing regenerating axons at early regeneration stages was that dorsotemporal and dorsonasal axons differ in their distribution over tectum. To quantify this observation, the numbers of dorsotemporal and dorsonasal axons were determined at six representative regions in six individual tecta for each group and the data of the six tecta were pooled. Table 1 gives the number of dorsotemporal and dorsonasal axons in regions 1-6 and Figures 13 and 14 illustrate their distribution diagrammatically.

The number of labeled dorsotemporal fibers declined drastically from rostral to caudal tectal regions. On the ventral hemitectum, $40 \%$ of all fibers were present in rostral region 


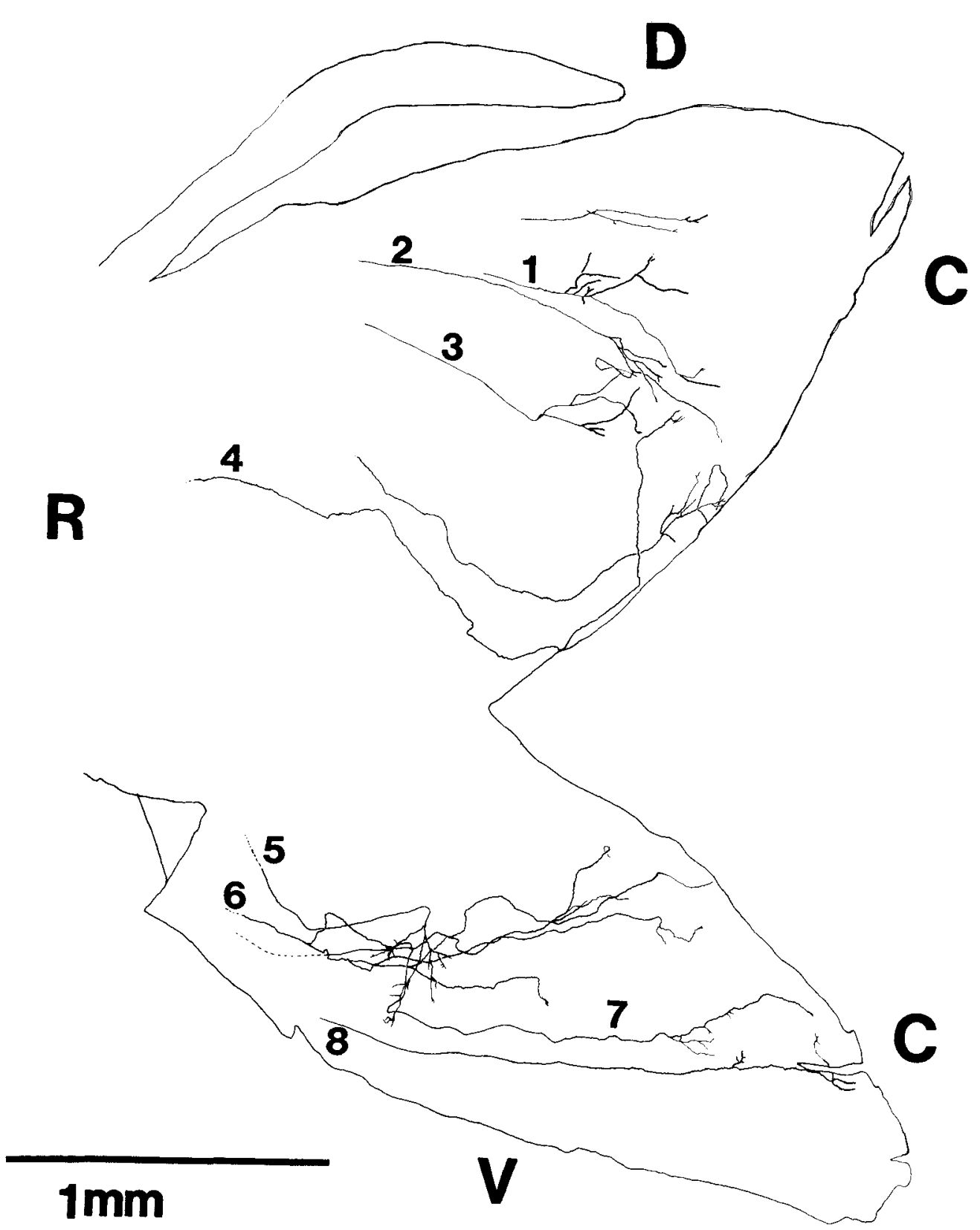

Fig. 12. Camera lucida tracings of branching dorsonasal axons from Figure 11. The position of axons 1-8 are indicated in the drawing of the tectum. The axons carry an abundance of growth cones and filopodia. Growth cones are exemplified by arrows on 3 and 6 .

TABLE 1. Number of Regenerating Dorsotemporal (DT) and Dorsonasal (DN) Axons: Early Regeneration Stages ${ }^{1}$

\begin{tabular}{|c|c|c|c|c|c|c|c|c|c|}
\hline \multirow[b]{2}{*}{ Region } & \multicolumn{4}{|c|}{ Ventral hemitectum } & \multicolumn{4}{|c|}{ Dorsal hemitectum } & \multirow[b]{2}{*}{$\Sigma_{\mathrm{D}+\mathbf{v}}$} \\
\hline & 1 & 2 & 3 & $\Sigma_{\mathrm{V}}$ & 4 & 5 & 6 & $\Sigma_{\mathrm{D}}$ & \\
\hline $\mathrm{T}$ & 87 & 32 & 8 & 115 & 54 & 26 & 11 & 91 & 218 \\
\hline DN & 47 & 46 & 31 & 124 & 54 & 48 & 27 & 129 & 253 \\
\hline
\end{tabular}

${ }^{1}$ Numbers (N) of regenerated dorsotemporal (DT) and dorsonasal (DN) axons at representative regions 1-6. Data were collected from six tectal whole mounts between 20 and 36 days after optic nerve section for each group. The fourth and seventh column give the sum $(\Sigma)$ of axons over the ventral $\left(\Sigma_{V}\right)$ and dorsal $\left(\Sigma_{D}\right)$ hemitectum, and the last column includes the total number of axons for each group $\left(\Sigma_{\mathrm{V}+\mathrm{D}}\right)$
$1,14 \%$ over region 2 , and only $4 \%$ in caudal region 3. On the dorsal hemitectum, rostral region 4 contained $25 \%$ of all fibers, midtectal region 5 contained $12 \%$, and the caudal region 6 only $5 \%$.

The number of dorsal fibers did not change markedly from the two rostral regions 1 and 4, with $19 \%$ and $21 \%$, respectively, to the midtectal regions 2 and 5 with $18 \%$ and $19 \%$. The fiber number fell at caudal regions 5 and 6 to $12 \%$ and $11 \%$, respectively.

The tracing of regenerating axons at early regeneration stages had revealed that axons take similar routes to their target as axons at late-regeneration stages (Stuermer, ' $87 \mathrm{~b}$, companion paper). Dorsotemporal and dorsonasal axons 

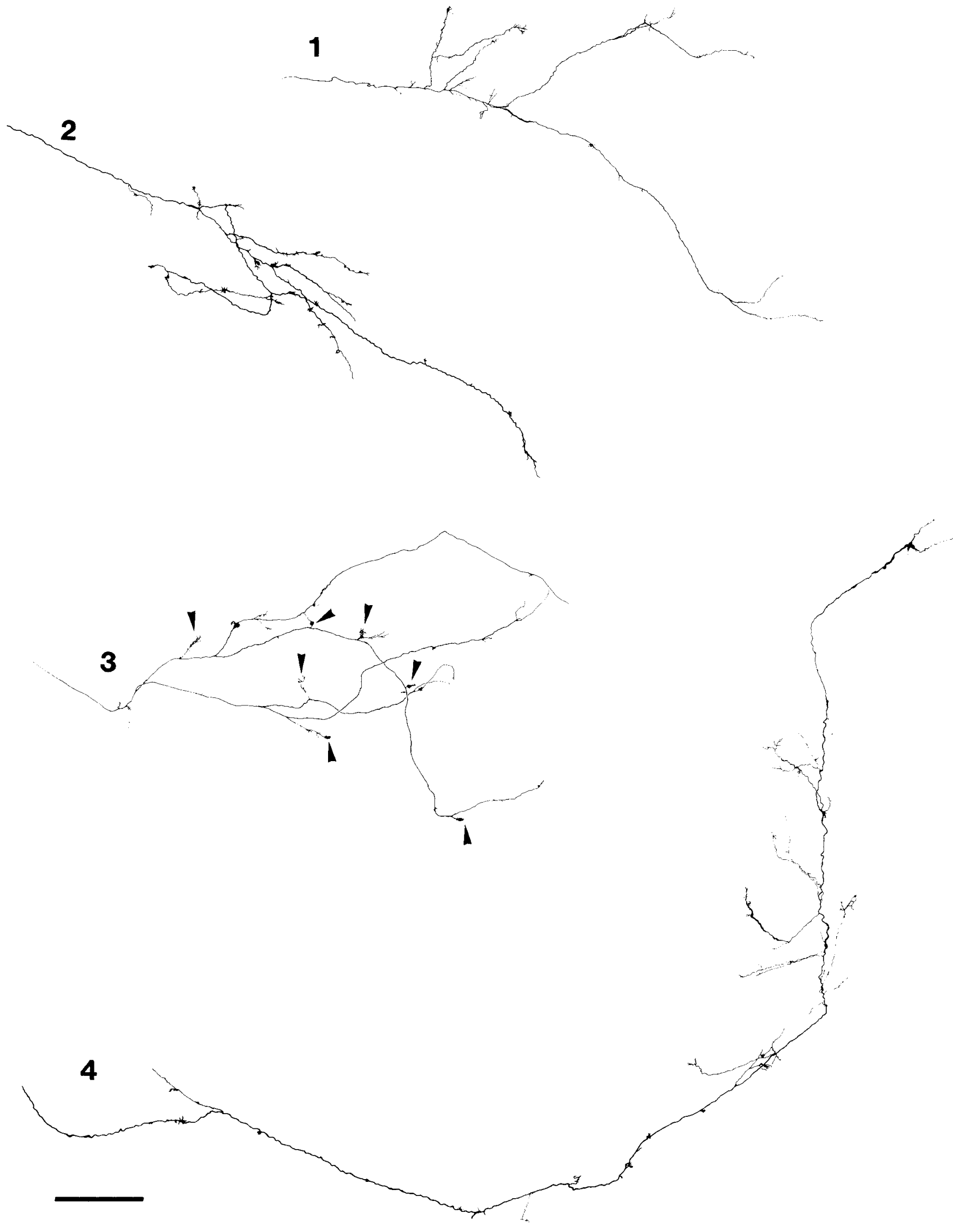

Figure 12 continued 

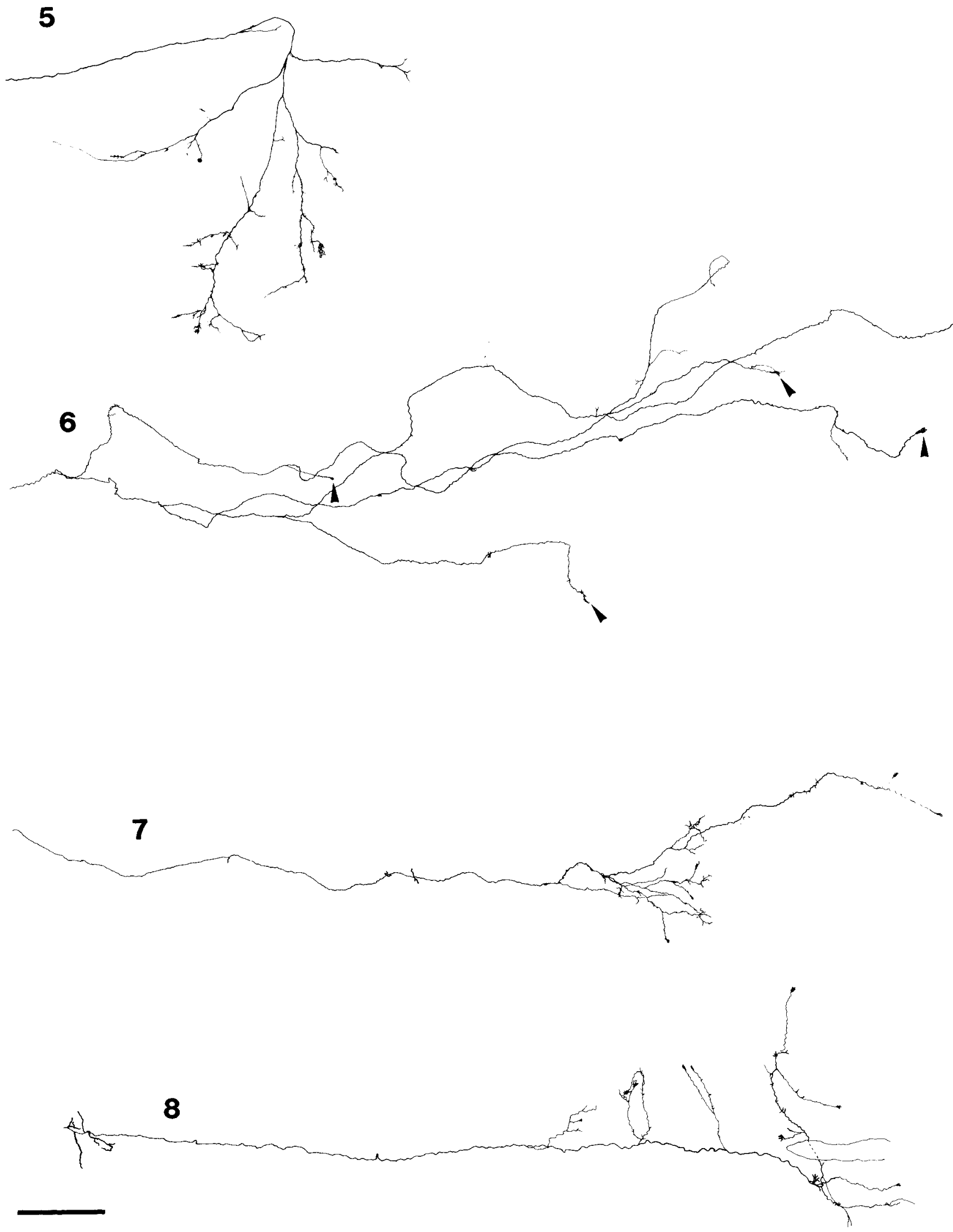

Figure 12 continued 


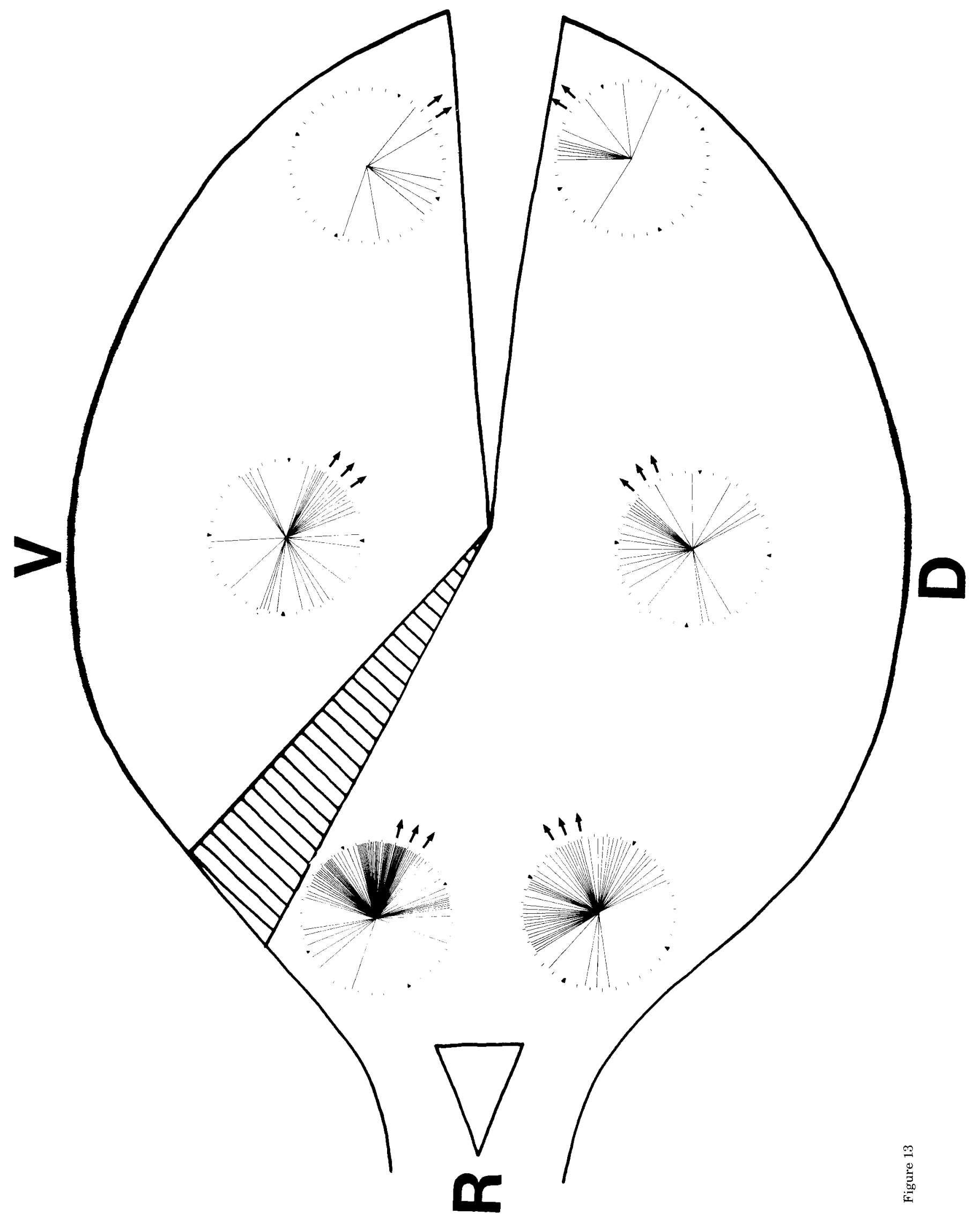




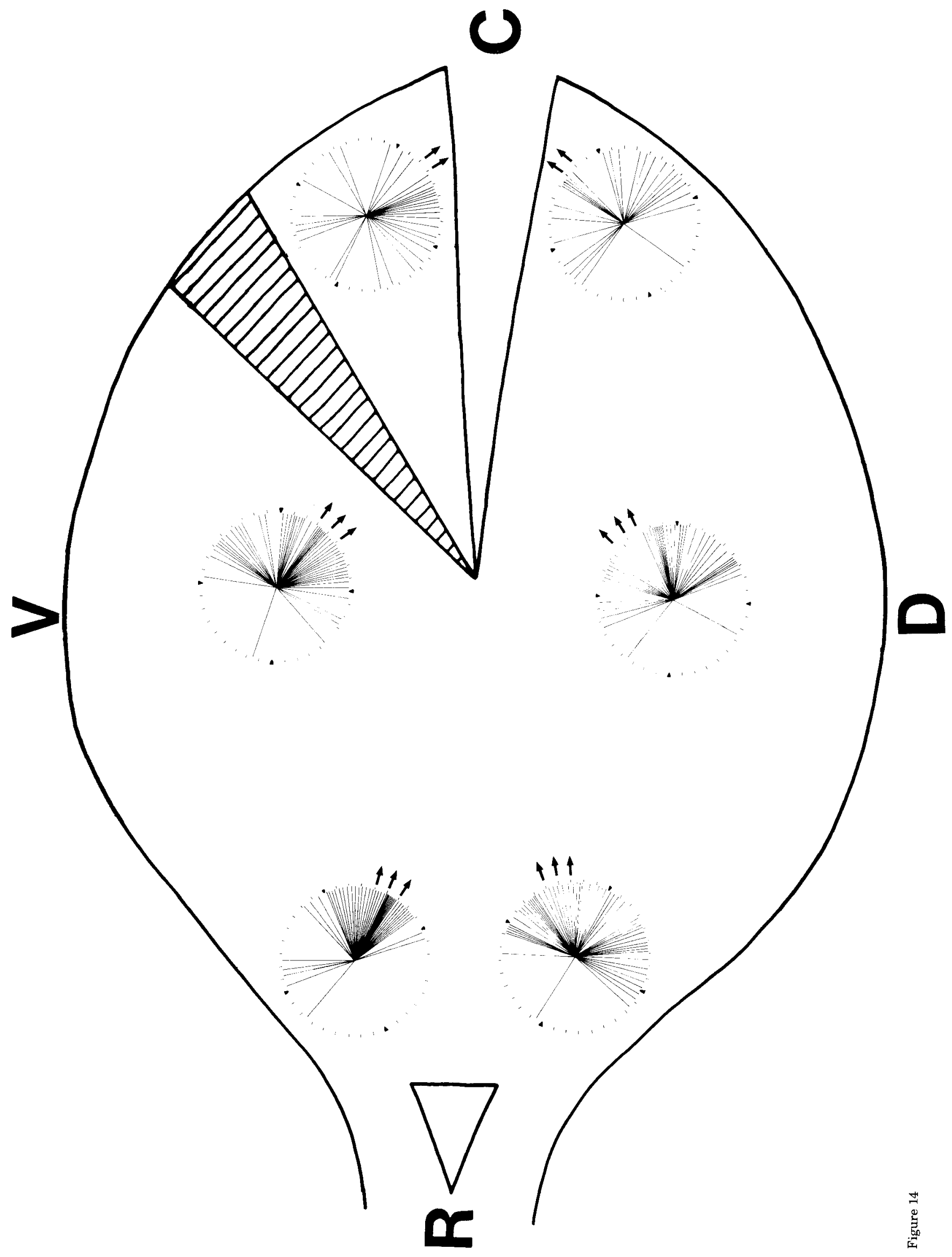


travel preferentially along the curved routes of the previous fascicles and when outside the fascicles some began to establish routes related to the direction of the target. However, different from axons at late-regeneration stages, numerous axons at early regeneration stages had not yet reached their target and branched on their course through tectum.

Therefore, the plots in Figures 13 and 14 showing the directions of dorsotemporal and dorsonasal axons from six tecta exhibit a wider range of orientations than comparable plots at late-regeneration stages (Figs. 7, 8 in Stuermer, ' $87 \mathrm{~b}$, companion paper). However, a preference for certain directions is nevertheless apparent. The majority of dorsonasal axons had directions ranging over $180+90^{\circ}$ in regions $1,2,4$, and 5 , which implies that most were directed in a caudal rather than rostral direction.

Dorsotemporal axons at comparable regions shared similar directions to some extent. However, part of the growing dorsotemporal axons had established target-directed orientations and those are represented at sites 4 and 5 by direc tions between 30 to $90^{\circ}$ and at site 2 by directions of $0+$ $45^{\circ}$. Axons of such orientation composed $38 \%$ at site $4,37 \%$ at site 5 , and $37 \%$ at site 2 . Dorsonasal axons of similar orientations composed only $11 \%$ at site $4,10 \%$ at site 5 , and $11 \%$ at site 2 .

\section{DISCUSSION}

This study has investigated the routes and the morphol ogy of regenerating retinal axons in the goldfish tectum at early regeneration stages $10-36$ days after optic nerve section. Regenerating axons in normal or abnormal routes navigate either with one or a few growth cones at their tips or they sprout a variable number of side branches or emit long branches at their ends. The branching axons are equipped with an abundance of growth cones and filopodia on their shafts and their branches. Dorsotemporal axons occupy and branch preferentially in the rostral tectal half whereas dorsonasal axons course into the caudal tectum and branch preferentially there. This differential distribution of dorsotemporal and dorsonasal axons was seen at 14 days after optic nerve section-that is, shortly after the invasion of the first axons into tectum-as well as over all subsequent periods.

\section{Technical considerations}

Satisfactory labeling of regenerating retinal axons at early regeneration stages was achieved by prolonging the time between HRP application and sacrifice of the fish to 4 or 5 days. Although the axons are severed when the HRP is placed into retina, they did not exhibit any visible signs of degeneration. Instead, fragile elements such as growth cones and filopodia appear completely stained and morphologically well preserved. These observations are consistent

Figs. 13, 14. Six polar plots showing the number and the orientations of labeled regenerated axons, collected form six tectal whole mounts. Each individual axon is represented as a black line. The retinotopic target region is indicated as a sector with diagonal lines. The directions of the fascicles are indicated by arrow.

Fig. 13. Regenerated dorsotemporal axons. The number of axons declines from rostral over midtectal to caudal regions (compare Table 1). Axons had various orientations.

Fig. 14. Regenerated axons, Axons were similar over rostral and midtec tal regions (compare Table 1) but declined over caudal regions. Most axons in rostral and midtectal regions were limited to a range of $180^{\circ}\left(180+90^{\circ}\right)$ with a study on growth cones in the frog brain in which they retained their normal appearance at least for 2 days after separation from their cell body (Scalia and Matsumoto, '85). Axons in tissue culture, which had been separated from their cell body, maintained their normal appearance for several hours (Hughes, '53; Shaw and Bray, '77; Wessel et al., '78), and these properties probably apply also to axons in vivo. Nevertheless, it is surprising that axons in vivo can survive for such extended time periods as 4-5 days.

We cannot exclude the possibility that injury to the retinal axons in retina may induce or accelerate the extension of branches and growth cones from axonal segments in tectum. However, although all axons are subjected to the same treatment, a large number did not show any sign of branching. Further, induction of branches was not observed on axons between 10 and 14 days, nor on axons at lateregeneration stages or on normal axons. Therefore, it is most likely that branching is not a consequence of injury.

\section{The trajectories and morphologies of regenerating axons}

By morphological criteria regenerating axons at early regeneration stages exhibit diverse behaviors to traverse the tectum. There were axons that navigated through the tectum led by growth cones at their distal tips whereas other axons branched profusely. This implies that branching may not be obligatory for all axons to pioneer their path. None of the axons branched in the superficial fascicle layer stratum opticum (SO).

As proposed in the preceding paper (Stuermer, ' $87 \mathrm{~b}$ ), the routes of the fascicles may represent major highways (Summerbell and Stirling, '81; Tosney and Landmesser, '84) through the tectum, which could allow for rapid axonal elongation. It would be of interest to test whether the fascicle layer contains particular growth-permissive substances, such as laminin, which has been shown to allow for rapid axonal elongation (Roger et al., '83; Adler et al., '85; Vielmetter, '86). Laminin increases in concentration in the optic nerve and tract during axonal regeneration (Hopkins et al., '85). Axonal growth through the meshwork of stratum fibrosum et griseum superficiale (SFGS) may occur at slower rates combined with sampling of the tectal re gions. It is in the SFGS where axons undergo course corrections to redirect their path toward their target and where pathfinding is for some axons connected with the emittance of side branches.

The branching axons carried a surprisingly large number of growth cones on their shaft and on their collaterals. The occurrence of multitudes of growth cones suggests that exploratory searching may take place simultaneously over extended stretches of the axons, which enables the axon to sample the tectal territory widely. The tectal area covered by axons with the longest branches was at least $400 \times 500$ $\mu \mathrm{m}$, which is approximately a twentieth of the tectal surface. The whole mounts give static images of the growing axons. Only real-time observations in tissue culture or in the living animal would permit us to follow the dynamics of these sampling events. In tissue culture, branching and the creation of numerous growth cones do not occur, nor when regenerating axons grow on substrates such as laminin, fibronectin, and various others (Landreth and Agranoff, '76; Vielmetter et al., '86). Axons growing on these substrates resemble those in the upper fascicle layer in that they have rather straight trajectories and usually carry one 
or at best two growth cones at their ends. Further experiments will reveal whether axons might begin to branch when grown on substrates derived from the synaptic layer of tectum.

Most branches except for the terminal abors are transitory extensions since they are absent on axons at late regeneration stages of 6 months and more (Fujisawa, ' 81 ; Fujisawa et al., '82; Stuermer, '87b). At late-regeneration stages, axons were smooth and ended in terminal arbors that were generally located at retinotopically appropriate regions (Stuermer, '87b). Branching at early stages occurred anywhere in the tectum and was not confined to the retinotopic termination region or its vicinity. It is conceivable that some axons that branch over the retinotopic region between 25 and 32 days may develop into mature terminal arborizations. However, it is unlikely that the early axonal ramifications at ectopic sites are molded directly into mature terminal arbors. Rather they may serve to explore the tectal territory and enable the axon to seek out the direction of the target (Fujisawa et al., '82). The branches may be sent out randomly and repeatedly into various directions (Sakaguchi and Murphey, '85). We sug gest that the axons elongate in the direction of the branches with proper orientations whereas other branches may be withdrawn or eliminated. Thus, the axons achieve targetdirected orientations by preferential selection of appropriately oriented branches (Fujisawa et al., '82).

Elaborate terminal arbors resembling those at long regeneration stages or those in normal fish (Stuermer, '84; Schmidt, '85) were reliably discerned from 32 days onward and they were always at or in the vicinity of the retinotopic region. Their appearance correlates with the time at which it becomes possible to record a retinotopically organized projection from tectum electrophysiologically (Schmidt et al., '83).

Although the growing retinal axons explore the tectal territories widely, their paths through the tectum are not random. The first ingrowing dorsotemporal axons had a higher preference for the more appropriate rostral tectum, whereas dorsonasal axons progressed immediately into cau dal tectal regions. This preferential distribution was maintained through all subsequent regeneration periods when more axons returned to tectum. These observations made on individual tectal whole mounts were substantiated by a quantitative evaluation of the number of dorsotemporal and dorsonasal axons. Our data confirm earlier findings in which the distribution of radioactively labeled or wheat germ agglutinin (WGA-HRP)-stained axons were reconstructed from tectal serial sections (Meyer, '80; Meyer et al., '85). They allow for the conclusion that the growing temporal and nasal axons have a higher affinity for their appropriate tectal halves.

The ability of regenerating axons to discriminate between appropriate and inappropriate territories exceeds that of half-tectal recognition (Fujisawa et al., '82; Meyer et al., '85). This is demonstrated by the fact that regenerating axons are able to undergo course corrections to grow into the direction of their target (Stuermer, '87b) and ultimately terminate at their retinotopic target sites (Schmidt, '78; Meyer, '80; Meyer et al., '85; Taylor and Gaze, '85; Stuermer, ' $87 \mathrm{~b}$ ). These findings are consistent with the concept that retinal axons and tectal cells carry position-dependent cellsurface markers (Sperry, '63) that are laid down in graded concentration over the retinal and tectal tissue (Gierer, '81; Bonhoeffer and Huf, '82; Bonhoeffer and Gierer, '84). Ac- cording to these models, the growing axons interact with the surfaces of tectal cells and are guided into regions with sets of markers that match or are complementary to their own. The gradient theory is an extension of Sperry's chemospecificity theory (Sperry, '63). It is the only concept that predicts that even misrouted axons-which are far away from their normal sites-can achieve target-directed routes. This concept also accounts for the result that axons cross freely other axons when they undergo course corrections and proceed toward their target.

If in contrast numerous position-specific tectal markers would be restricted to distinct groups of tectal cells-instead of being laid down in a graded fashion-a different mode of axonal growth would be expected. Under these circumstances axons should search for their appropriate locus by trial and error until they happen to meet their appropriate sites by chance. However, the foregoing study has shown that axons do not err through tectum randomly.

Other models proposed that axons are able to position their terminal arbors in retinotopic order by means of specific fiber interactions and maintenance of neighborhood relationships (Cook and Horder, '77; for review see Frazer and Hunt, '80). In normal fish, axons do preserve their pathway. Regenerating axons, however, travel in abberrant routes. Axons that used to be neighbors in retina are often widely separated from one another (Stuermer, '86). If regenerating axons would only search for their neighbors one would expect that misrouted axons would become associated into groups at various ectopic sites in tectum. It is difficult to conceive how axons would be able to rejoin at the retinotopic target sites without directional cues from tectum.

\section{Comparison with related findings}

The multitude of branches on regenerating axons in the tectum accounts, at least in part, for the increase of retinal axon processes determined electron microscopically at early regeneration stages (Murray and Edwards, '82). Our observations that some axons produce long branches and thus create ramifications of unusually large dimensions are consistent with similar findings by Schmidt ('85). However, Schmidt's analysis was restricted to measurements of axonal arborizations and he did not relate the position of the arborizations to the axon's origin in retina nor did he consider the trajectories of regenerating axons toward their target.

The trajectories of regenerating axons in goldfish resemble those in the newt (Fujisawa et al., '82). In both species they travel in abnormal routes, send out transient side branches on their course through tectum, and ultimately reach their target, where they produce densely branched terminal arbors (Fujisawa et al., '82). In the newt, however, only misrouted axons were reported to branch, whereas normally routed axons remained smooth (Fujisawa et al., '82). In goldfish, branching was common to a fraction of both normally routed and misrouted axons.

To assess the order of the tectal projection Meyer et al. ('85) made injections of WGA-HRP into small sites in retina and determined the distribution of labeled axon profiles in serial sections. WGA-HRP is reported to be accumulated into the endings of axons (Shook et al., '83; Meyer et al., '85). The endings were widespread over tectum up to 25 days whereupon they gradually condensed over subsequent weeks to appropriate tectal territories. Rankin and Cook ('86) also showed a diffuse projection at early regeneration 
periods. Following tectal injections of WGA-HRP, which is believed to be taken up by axonal endings, ganglion cells in retina were transiently scattered widely up to 40 days after optic nerve section, whereas they were confined to small sites in the normal or at late-regeneration stages (Cook, '83; Stuermer and Easter, '84; Rankin and Cook, '86). Our study has shown that part of the terminal endings that are transiently at inappropriate regions are branches, growth cones on axonal tips, on the axonal shaft and on branches. Since these endings, derived from a small group of ganglion cells, were present in all regions of tectum, they can account at least to some extent for the early diffuse projection (Meyer et al., '85; Rankin and Cook, '86).

Several studies reported that the restoration of refined retinotopic order is achieved as long as the regenerating axons retain their normal pattern of impulse activity (Schmidt et al., '83; Schmidt, '85; Rankin and Cook, '86). When activity is blocked by tetrodotoxin (TTX) (Meyer, '83; Schmidt and Edwards, '83) or when fish are reared under strobe-light conditions during the regeneration of the optic nerve (Cook and Rankin, '86), the map is topographically organized on a gross level but never reaches its normal precision (Meyer, '83; Schmidt and Edwards, '83; Cook and Rankin, '86). This implies that either axons form terminal arbors at ectopic sites or that the axons maintain collaterals that would normally be withdrawn (Schmidt, '85; Cook and Rankin, '86). Based on our current results we will test whether ectopic side branches will persist on axons that regenerate in the presenc of TTX.

\section{Comparison to retinal axons in development}

In the Xenopus embryo the growing axons were reported to be retinotopically organized throughout their path (Holt and Harris, '83), to approach their target from ectopic positions in straight lines (Harris, '86), and to deploy their terminal arbors at appropriate retinotopic sites (Holt and Harris, '83; Sakaguchi and Murphy, '85). The embryonic axons exhibited only a few short collaterals on their shaft (Sakaguchi and Murphy, '85). Similarly, retinal axons in the cat embryo that grow to the lateral geniculate nucleus coursed directed toward their target (Sretaven and Shatz, '86). Numerous short side branches protruded from the axons prior to the axon's arrival at its target. The axons finally terminated in bushy terminal arbors whereupon the side branches disappeared (Sretavan and Shatz, '86). A similar sequence of events was also noted for chick retinotectal axons (Thanos and Bonhoeffer, '87). Thus, during normal development in Xenopus, the chick and the cat retinal axons appear to course in orderly routes, emit transient collaterals, and then develop terminal arbors within a fixed framework at their retinotopic target.

To our knowledge growing axons in tectum have not been pursued during embryonic development of fish. We are currently involved in labeling retinal axons in the guppy, goldfish, and zebrafish embryos. Preliminary results indicate that part of the embryonic axons grow rather directly into the direction of their target and end in small but elaborate terminal arbors. A fraction of the axons were seen to emit collaterals from their shaft which covered approximately a fourth of the tectal surface. These data suggest that excessive branching may be common to a fraction of both the retinal axons in early regeneration stages and in development. However, while axons in normal development generally grow in orderly and stereotyped routes toward their target, regenerating axons establish highly abnormal and circuitous trajectories.

\section{LITERATURE CITED}

Adler, R., J. Jerdan, and A.T. Hewitt (1985) Responses of culture of neural retinal cells to substratum-bound laminin and other extracellular ma trix molecules. Dev. Biol. 112:100-114

Attardi, D.G., and R.W. Sperry (1963) Preferential selection of central path ways by regenerating optic fibers. Exp. Neurol. 7:46-64

Bonhoeffer, F., and J. Huf (1982) In vitro experiments on axon guidance demonstrating an anterior-posterior gradient on the tectum. EMBO J. 1:427-431.

Bonhoeffer, F., and A. Gierer (1984) How do retinal axons find their targets on tectum? TINS:378-381.

Cook, J.E., and J.T. Horder (1977) The multiple factors determining retinotopic order in the growth of optic fibers into the optic tectum. Philos. Trans. R. Soc. Lond. [Biol.] 278:261-276.

Cook, J.E. (1983) Tectal paths of regenerated optic axons in the goldfish: Evidence from retrograde labelling with horseradish peroxidase. Exp. Brain Res. 51:433-442.

Cook, J.E., and E.C. Rankin (1984) Use of a lectin-peroxidase conjugate (WGA-HRP) to assess the retinotopic precision of goldfish optic termi nals. Neurosci. Lett. 48:61-66.

Cook, J.E., and E.C.C. Rankin (1986) Impaired refinement of the regener ated retinotectal projection of the goldfish in stroboscopic light: A quan titative study. Exp. Brain Res. 63:421 430 .

Fawcett, J.W., and R.M. Gaze (1981) The organization of regenerating axons in the Xenopus optic nerve. Brain Res. 229:487-490.

Frazer, S.E., and R.K. Hunt (1980) Retinotectal specificity: Models and experiments in search of a mapping function. Annu. Rev. Neurosci 3:319-352.

Fujisawa, H. (1981) Persistence of disorganized pathways and tortuous tra jectories of the regenerating retinal fibers in the adult newt. Cynops pyrrhogaster. Dev. Growth Differ. 23:215-219.

Fujisawa, H., N. Tani, K. Watanabe, and Y. Ibata (1982) Branching of regenerating retinal axons and preferential selection of appropriate branches for specific neuronal connection in the newt. Dev. Biol. 90:4357.

Gaze, R.M. (1970) The formation of nerve connections. London: Academic Press.

Gierer, A. (1981) Development of projections between areas of the nervous system. Biol. Cybern. 42:69-78.

Harris, W.A. (1986) Homing behavior of axons in the embryonic vertebrate brain. Nature 320:266-269.

Holt, C.E., and W.A. Harris (1983) Order in the initial retinotectal map in Xenopus: A new technique for labelling growing nerve fibres. Nature 301:150-152.

Hopkins, J.M., T.S. Holevinski, J.P. MacCay, and B.W. Agranoff (1985) Laminin and optic nerve regeneration in goldfish. J. Neurosci. 5:30303038.

Horder, T.J. (1974) Changes of fiber pathways in the goldfish optic tract following regeneration. Brain Res. 72:41-52.

Hughes, A. (1953) The growth of embryonic neurites. A study on cultures of chick neural tissue. J. Anat. 87:150-162.

Humphrey, M.F., and L.D. Beazley (1982) An electrophysiological study of the early stages of optic nerve regeneration in Hyla moorei. Brain Res. 239:595-602.

Jacobsen, U., and R.M. Gaze (1965) Selection of appropriate terminations by regenerating optic fibers in the adult goldfish. Exp. Neurol. 13:418430.

Landreth, G.E., and B.W. Agranoff (1979) Explant culture of adult goldfish retina: A model for the study of CNS regeneration. Brain Res. 161:39_ 53.

Meyer, R.L. (1980) Mapping the normal and regenerating retinotectal projection of goldfish with autoradiographic methods. J. Comp. Neurol. 189:273-289.

Meyer, R.L. (1983) Tetrodotoxin inhibits the formation of refined retinotopography in goldfish. Dev. Brain Res. 6:293-298.

Meyer, R.L., K. Sakurai, and E. Schauwecker (1985) Topography of regen erating optic fibers in goldfish traced with local wheat germ injectories into retina: Evidence for discontinuous microtopography in the retinotectal projection. J. Comp. Neurol. 239:27-43.

Murray, M., and M.A. Edwards (1982) A quantitative study of the reinnervation of the goldfish optic tectum following optic nerve crush. J. Comp. Neurol. 209:363-373.

Northmore, D.P.M., and T. Masino (1984) Recovery of vision in fish after optic nerve crush: A behavioral and electrophysiological study. Exp. Neurol. 84:109-125. 
Rankin, E.C.C., and J.E. Cook (1986) Topographic refinement of the regen erating retinotectal projection of the goldfish in standard laboratory conditions. A quantitative WGA-HRP study. Exp. Brain Res. 63:409 420 .

Rogers, S.L., P.C. Letourneau, S.L. Palm, J. McCarthy, and L.T. Furcht (1983) Neurite extension by peripheral and central nervous system neurons in response to substratum-bound fibronectin and laminin. Dev. Biol. 98:212-220.

Sakaguchi, D.S., and R.K. Murphey (1985) Map formation in the developing Xenopus retinotectal system: An examination of ganglion cell terminal arborizations. J. Neurosci. 5:3228-3245.

Scalia, F., and D.E. Matsumoto (1985) The morphology of growth cones of regenerating optic nerve axons. J. Comp. Neurol. 231:323-338.

Schmidt, J.T. (1978) Retinal fibers alter tectal positional markers during the expansion of the half retinal projection in goldfish. J. Comp. Neurol 177:279-300.

Schmidt, J.T. (1985) Formation of retinotopic connections: Selective stabilization by an activity-dependent mechanism. Cell. Mol. Neurobiol. 5:65 84.

Schmidt, J.T., and D.L. Edwards (1983) Activity sharpens the map during the regeneration of the retinotectal projection in goldfish. Brain Res. 269:29-39

Schmidt, J.T., D.L. Edwards, and C.A.O. Stuermer (1983) The reestablishment of synaptic transmission by regenerating optic axons in goldfish Time course and effects of blocking activity by intraocular injection of tetrodotoxin. Brain Res. 269:15-27.

Shaw, G, and D. Bray (1977) Movement and extension of isolated growth cones. Exp. Cell Res. 104:496-504

Shook, B.L., B.P. Abramson, and L.M. Chalupa (1983) An analysis of the transport of WGA-HRP in the cat's visual system. J. Neurosci. Methods 11:65-77.

Sperry, R.W. (1963) Chemoaffinity in the orderly growth of nerve fiber patterns and connections. Proc. Natl. Acad. Sci., USA 50:703-709.

Sretavan, D.W., and C.J. Shatz (1986) Prenatal development of retinal ganglion cell axons: Segregation into eye-specific layers within the cat's lateral geniculate nucleus. J. Neurosci. 6:234-251.

Stuermer, C.A.O. (1984) Rules for retinotectal terminal arborizations in the goldfish optic tectum. A wholemount study. J. Comp. Neurol. 229:214322 .

Stuermer, C.A.O. (1986) Pathways of regenerated retinotectal axons in goldfish. I. Optic nerve, tract, and tectal fascicle layer. J. Embryol. Exp. Morph. 93:1-28.
Stuermer, C.A.O. (1987a) Navigation of Normal and Regenerating Axons in the Goldfish Tectum. Oxford University Press (in press).

Stuermer, C.A.O. (1987b) Trajectories of regenerating retinal axons in the goldfish tectum: I. A comparison of normal and regenerated axons at late regeneration stages. J. Comp. Neurol. 265:000-000.

Stuermer, C.A.O., and S.S. Easter (1984) A comparison of the normal and regenerated retinotectal pathways of goldfish. J. Comp. Neurol. 223:5776.

Stuermer, C.A.O., M. Beckmann, and A. Habring (1986a) Morphology of regenerating retinal axons and growth cones in the goldfish tectum. The Making of the Nervous System. Kent, Abstr. p. 30 .

Stuermer, C.A.O., M. Wizenmann, and A. Kelber (1986b) Navigation of regenerating retinotectal axons in goldfish. Soc. Neurosei. Abstr. 12:389.

Stuermer, C.A.O., M. Beckmann, and E. Kalko (1985) Morphology of regen erated retinal axonal terminal arbors in the goldfish tectum. Soc. Neurosci. Abstr. 11:421.

Summerbell, D., and R.V. Stirling (1981) The innervation of dorsoventrally reversed chick wings: Evidence that motor axons do not actively seek out their appropriate targets. J. Embryol. Exp. Morphol. 61:233-247.

Taylor, J.S.H., and R.M. Gaze (1985) The effects of the fibre environment on the paths taken by regenerating optic nerve fibers in Xenopus. J. Embryol. Exp. Morphol. 89:383 401.

Thanos, S., and F. Bonhoeffer (1987) Axonal arborization in the developing chick retinotectal system. J. Comp. Neurol. 261:155-164.

Tosney, K.W., and L.T. Landmesser (1984) Pattern and specificity of axonal outgrowth following varying degrees of chick limb bud ablation. J. Neurosci. 4:2518-2527.

Udin, S. (1978) Permanent disorganization of the regeneration optic tract in the frog. Exp. Neurol. 58:455-470.

Vielmetter, J. (1986) Auswachsen und Verhalten retinaler Ganglienzellaxone des Goldfisches in vitro. Der Einflu $\beta$ von Kulturbedingungen und Substraten. Diploma thesis, Tuebingen.

Vielmetter, J., B. Stolze, S. Henke-Fahle, C.A.O. Stuermer, and F. Bonhoeffer (1986) In vitro assay to test differential substrate affinity of growing axons. Neurosci. Lett. [Suppl.] 26:167.

Wessells, N.K., S.R. Johnson, and R.P. Nuttall (1978) Axon initiation and growth cone regeneration in cultured motor neurons. Exp. Cell Res. $117: 335-345$. 